\title{
Optimal Design and Energy Management of a Hybrid Power Generation System Based on Wind/Tidal/PV Sources: Case Study for the Ouessant French Island
}

\author{
O.H. Mohammed, Y. Amirat, M.E.H. Benbouzid and G. Feld
}

\begin{abstract}
Hybrid power generation systems have become a focal point to meet requirements of electric power demand. This kind of system combines several technologies and is considered as one of the appropriate options for supplying electricity in remote areas, such islands, where the electric utility is not available. It is one of the promising approaches due to its high flexibility, high reliability, higher efficiency, and lower costs for the same produced energy by traditional resources. Typically, hybrid power generation systems combine two or more conventional and renewable power sources. They will also incorporate a storage system. This chapter will focus on a typical hybrid power generation system using available renewables near the Ouessant French Island: wind energy, marine energy (tidal current), and PV. This hybrid system is intended to satisfy the island load demand. It will therefore explore optimal economical design and optimal power management of such kind of hybrid systems using different approaches: (1) Cascaded computation (linear programming approach); (2) Genetic algorithms-based approach; (3) Particle swarm optimization. In terms of economical optimization, different constraints (objective functions) will be explored for a given 25 years of lifetime; such as minimizing the Total Net Present Cost (TNPC), minimizing the Levelized Cost of
\end{abstract}

\author{
O.H. Mohammed ( $₫) \cdot$ M.E.H. Benbouzid \\ University of Brest, Institut de Recherche Dupuy de Lôme (FRE CNRS 3744 IRDL), \\ 3, Rue des Archives, 29238 Brest, France \\ e-mail: Omar-Hazem-Mohammed.Mohammed@univ-brest.fr \\ M.E.H. Benbouzid \\ e-mail: Mohamed.Benbouzid@univ-brest.fr \\ Y. Amirat · G. Feld \\ ISEN Brest, Institut de Recherche Dupuy de Lôme (FRE CNRS 3744 IRDL), \\ 20, Rue Cuirassé Bretagne, 29200 Brest, France \\ e-mail: Yassine.Amirat@isen-bretagne.fr \\ G. Feld \\ e-mail: Gilles.Feld@isen-bretagne.fr \\ O.H. Mohammed \\ North Technical University, Technical College of Mosul, Mosul, Iraq
}


Energy (LCE). The concept of reliability will also be explored to evaluate the hybrid system based on renewables to satisfy the island load requirements. In this chapter, the Equivalent Loss Factor (ELF) is considered.

Keywords Hybrid power generation system - Renewable energy - Optimal sizing - Island

\section{Introduction}

Nowadays, the renewable energy is evolving in the same manner as expansion of energy demand. As conventional plants are reaching the end of their useful lives, they are expected to replace by renewable energy resources and cleaner technology such as wind, solar, tidal, gas, etc. Although renewable energy penetration in electricity is expected to have a spectacular growth in the forthcoming years, it still however has very low participation rate compared to other nonrenewable energies. In addition, it is necessary to integrate the renewable energy technologies into the power grid so as to support it, raising therefore reliability, improving power quality, increasing efficiency, and decreasing fluctuations [1]. Many studies have investigated the potential contribution of renewables to global energy supplies, indicating that in the second half of the twenty-first century their contribution might range from the present figure of nearly $20 \%$ to more than $50 \%$ with the right policies in place. About 30\% contribution to world energy supply from renewable energy sources by year 2020 is reported in [2]. However, integrating those renewable energy resources into the grid is made more complex by a number of issues that are related to intermittent availability of those resources and to the electrical characteristics of the associated generators. To overcome these issues and to enhance the energy system reliability, these generation unit should be working together in two or more sources in the so-called hybrid system concept. Hybrid power station concept is not new, but has gained popularity and rapid development in the recent year. There are many types of hybrid energy systems including renewable and nonrenewable sources that have been considered. Figure 1 summarizes all the possible architectures and combinations including a grid connection. Nevertheless, it is essential that renewable energy hybrid systems to be cost-effective and achieve high reliability to meet the load requirements. Hence, designing a renewables-based hybrid energy system must fulfill different constraints. These constraints can be divided into two categories: The first category is a technical one and encompasses energy sources availability, generation components, battery systems state of charge, and electric load location. The second category is an economical one including reliability, flexibility, efficiency, and costs.

Various literature [3-5], has demonstrated that hybrid renewable electrical systems in off-grid applications are cheaply feasible in isolated areas. Moreover, environment can make a topology of hybrid system more efficient than another one. 


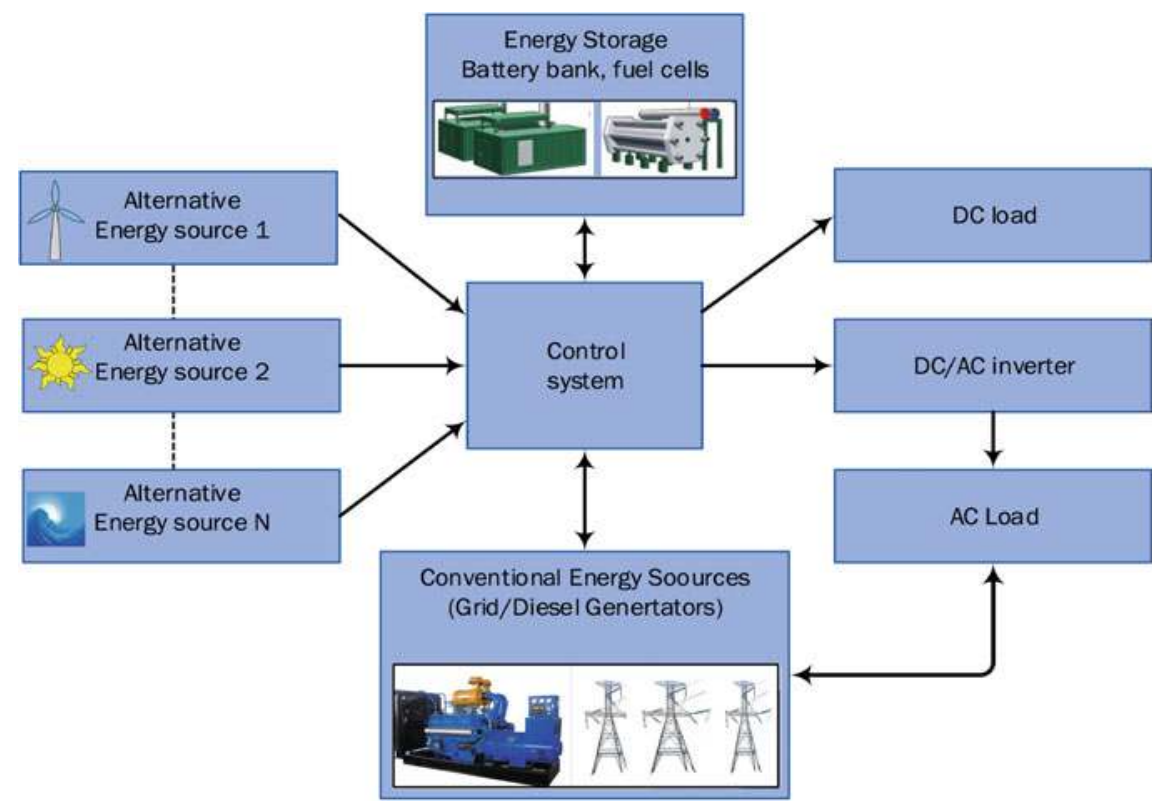

Fig. 1 Hybrid generation systems general architecture

For example, a hybrid system (Wind/Diesel/Battery) is ideal in areas where there are substantial wind resources rates all over the year [6]; since a photovoltaic hybrid system (Photovoltaic/Diesel/Battery) is perfect in areas with significant solar radiation. Hybrid renewable power generation systems optimal design is a very challenging task as far as most renewable energy resources are random and weather/climatic conditions-dependent. Figure 2 illustrates the general process of a hybrid generation system optimization. For that purpose, different techniques and various mathematical models have been used to design hybrid systems so as to reach various goals and get the optimization, such as particle swarm optimization technique (PSO), genetic algorithms (GA), fuzzy algorithms, cascade analysis, artificial neural network, etc. [7].

This chapter will focus on a typical hybrid power generation system using available renewables near the Ouessant French Island: wind energy, marine energy (tidal current), and PV as illustrated by Fig. 3. This hybrid power generation system is intended to satisfy the island load demand illustrated by Fig. 4. It will therefore explore optimal economical design and optimal power management of such kind of hybrid systems using different approaches: (1) Cascaded computation (linear programming approach); (2) Genetic algorithms-based approach; (3) Particle swarm optimization. In terms of economical optimization, different constraints (objective functions) will be explored for a given 25 years of lifetime; such as minimizing the Total Net Present Cost (TNPC), minimizing the Levelized Cost of Energy (LCE), etc. The concept of reliability will also be explored to evaluate the hybrid system ability to satisfy the island load requirements. In this chapter, the Equivalent Loss 


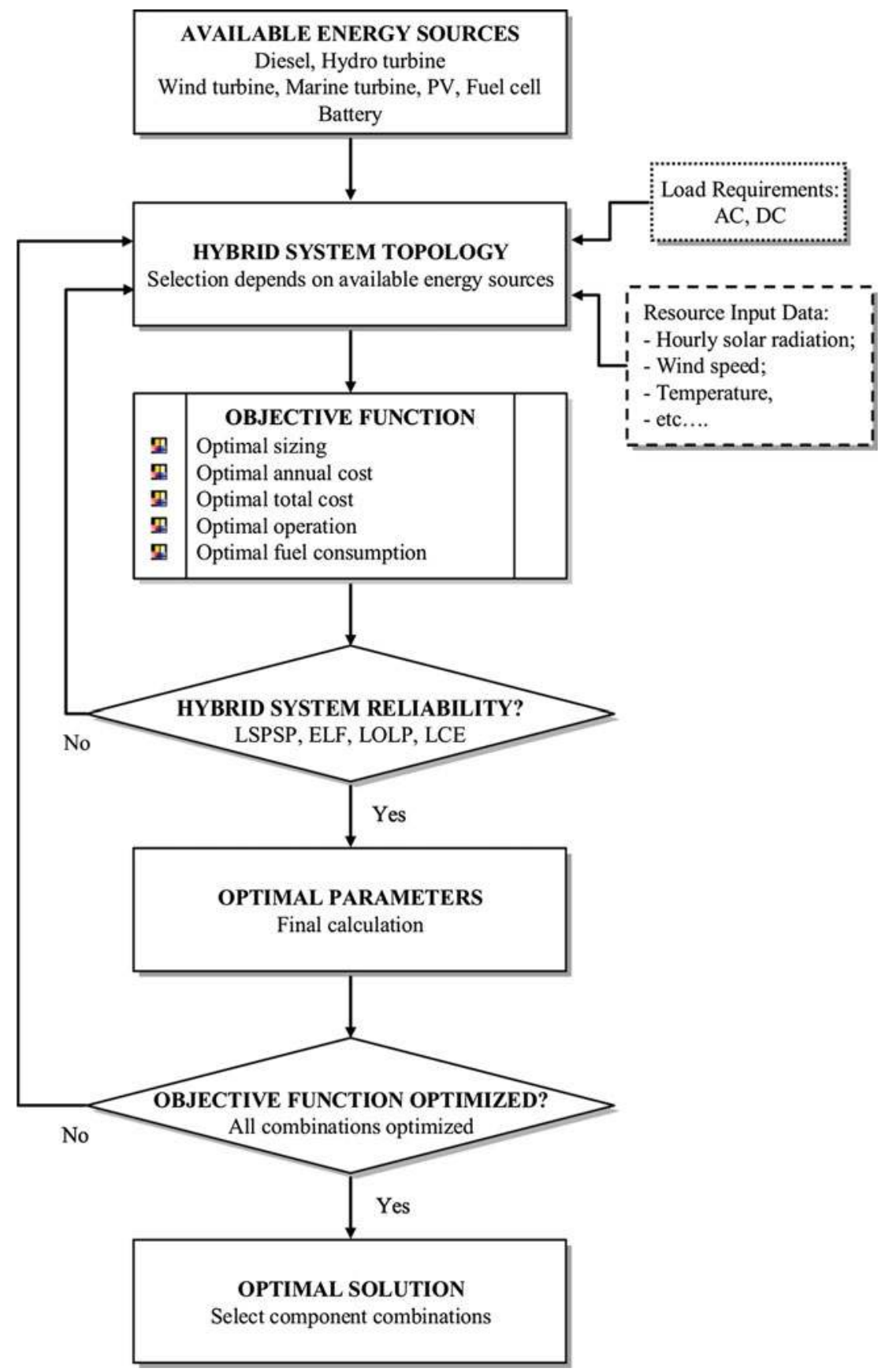

Fig. 2 Hybrid generation system optimization general model [10] 


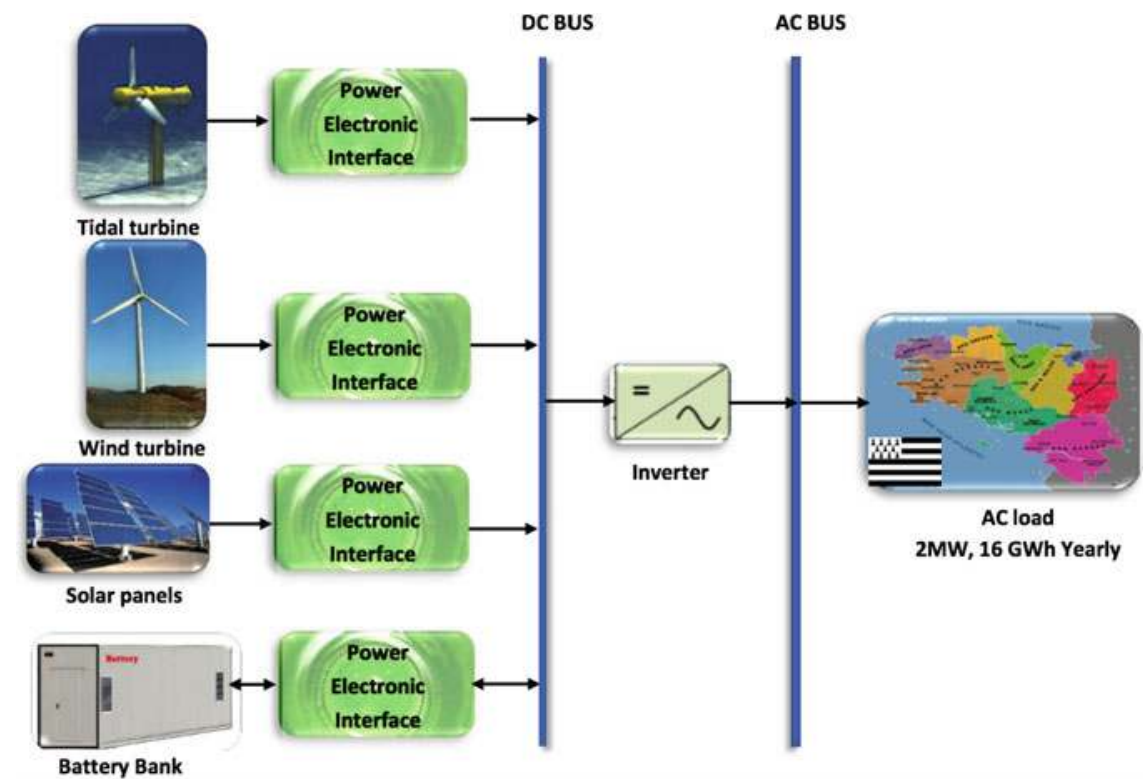

Fig. 3 Configuration of hybrid Wind/tidal/PV/battery stand-alone energy system
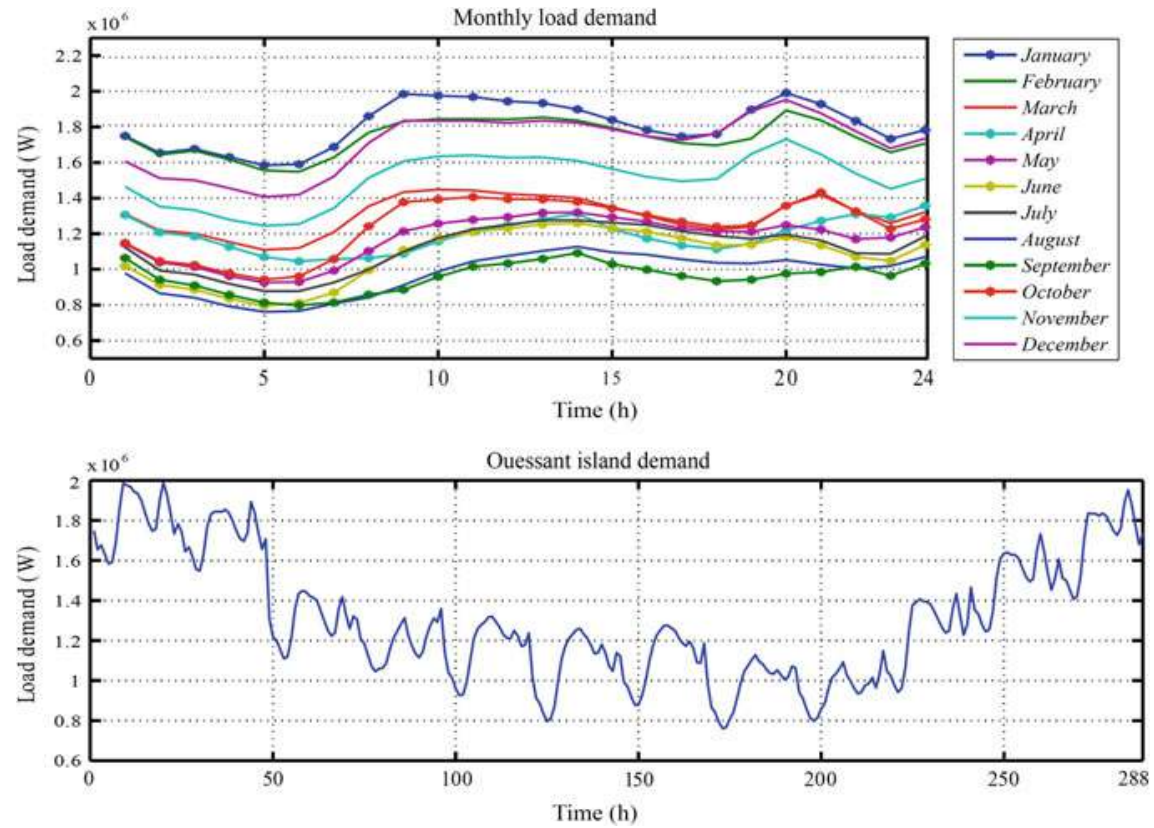

Fig. 4 Ouessant Island load demand 
Factor (ELF) is considered. This approach can be extended with no a priori to any islanded or off-grid sites. It should be mentioned that previous studies have already attempted to address islands typical issue of energy management using marine renewable energies [8, 9].

\section{Design, Analysis, and Optimization Software Tools for Hybrid Generation Systems}

In the existing literature, there are various software and design tools to evaluate and to optimize hybrid energy systems. Each of these available softwares and tools has their specific advantages and drawbacks. This section is therefore is devoted to briefly present the most commonly used software for hybrid energy systems design and optimization.

\subsection{RETScreen}

RETScreen is a free clean energy management software system for co-generation project feasibility analysis, and energy performance evaluation. The Ministry of Environment of Canada has released it. The first version was introduced for on-grid applications, the RETScreen PV model was currently upgraded to deal with off-grid applications. These include stand-alone, hybrid and water pumping systems. The software guides the users in the design of their systems, by giving initial estimates of an array, battery, or pump size. By modifying few of the system parameters, users have the ability to quickly screen the most helpful technology and system size depending upon the load, weather conditions, and season of use. It has capabilities for evaluating both financial and environmental costs, assists in the decision, determine, and make the most of the advantages of renewable energy technologies for any location around the world [11-13]. RETScreen has several worksheet for carrying out detailed project analysis, including energy modeling, cost analysis, emission analysis, financial analysis and sensitivity and risk analyzes sheets. It has a global climate data database of over 6000 ground stations (month wise solar irradiation and temperature data for the year), hydrology data, energy resource maps (such as wind maps), product data like solar photovoltaic panel information and wind turbine power curves. It also offers a link to the climate database of NASA. it is used for the analysis of various types of energy-efficient and renewable technologies (RETS) dealing with mainly energy production, life-cycle costs, and greenhouse gas emission reduction. RETScreen Plus is based upon an energy management software tool to study the energy performance.

The main limitations of RETScreen are: it does not consider the effect of temperature on PV performance analysis, the data sharing problem, limited options for search and sensitivity analysis, no possibility of time series data files and import 
retrieval, does not support more advanced estimations and visualization features $[12,14]$.

\section{$2.2 \quad L E A P$}

LEAP (Long Range Energy Alternatives Planning) was developed at the Stockholm Environment Institute in 2008. It is a widely used software tool for the analysis of energy policy and evaluation of the impact of climate change. It includes a scenario manager that can be used to describe individual measures. It allows investigating the economic potential for energy performance and low emission development strategies to reduce gas emission as $\mathrm{CO}_{2}$. It is mainly used to analyze national energy systems. It uses a yearly time step and time horizon may extend over a number of years (usually between 20 and 50 years). However, neither optimization nor controls are possible $[15,16]$.

\subsection{HYSIM}

HYSIM is a hybrid energy simulation model produced by Sandia National Laboratory of the US DOE. It is used for evaluating stand-alone off-grid hybrid systems consisting in PV panels, Diesel generators and battery storage combination with system reliability in 31 remote locations. The objective of this model was to look at increasing overall system reliability by adding PV and battery storage, in addition to financial analysis that LCOE, life-cycle, fuel cost, operation and maintenance costs. HYSIM appears to have been used up until $1996[17,18]$.

\section{4 iHOGA}

iHOGA (Improved Hybrid Optimization by Genetic Algorithms) is a software formerly known as HOGA (Hybrid Optimization by Genetic Algorithm), developed for the simulation and optimization of hybrid renewable energy systems. It has been developed at the University of Zaragoza (Spain) [19-21]. It is a single-purpose or multi-optimization software target hybrid renewable energy systems. It uses genetic algorithms to optimize the control strategies of hybrid systems consisting in PV panels, wind turbines, Diesel generators, batteries, hydraulic turbines, $\mathrm{H}_{2}$ tanks, electrolyzers, fuel cells, rectifiers, and inverters. The simulation is performed using one-hour intervals, during which all parameters remain constant. Optimization is obtained by minimizing the total cost of the system throughout its lifetime. However, this software allows for multi-objective optimization, where additional variables can also be minimized, such as the equivalent $\mathrm{CO}_{2}$ emissions or unmet load (energy not served). Since all these variables (costs, emissions or unmet load) are mutually against-productive in many cases, 
more than one solution is provided. Some of these solutions show better performance when applied to emissions or unmet load while other solutions are better suited for costs. It is used for controlling system components. Indeed, the command with iHOGA is limited to energy flow management strategies [12, 21, 22].

\section{$2.5 \quad$ ARES}

ARES (Autonomous Renewable Energy Systems) is a software designed by the Cardiff school of engineering (UK). It is applied to simulate PV/Wind hybrid systems with battery storage [20,23]. This software can calculate the system loss of load possibility and system autonomy by the prediction of the storage battery voltage if input load and essential weather profile are provided.

\subsection{SOMES}

The University of Utrecht (NL) developed SOMES (Simulation and Optimization Model for renewable Energy Systems). It is intended to simulate and to analyze the operation of a PV/Wind/Diesel hybrid system with batteries for storage. It allows economic analysis optimization of projects but it does not provide control systems. Optimal operating strategies and criteria for starting and stopping the Diesel generator are provided by the user [24, 25].

\subsection{RAPSIM}

RAPSIM (Remote Area Power Supply Simulator) is a windows-based software package developed by the Murdoch, University Energy Research Institute in Australia. It is intended to simulate PV arrays - wind turbines-Diesel generators with battery storage. It allows the user to select a hybrid system (PV and/or wind and/or Diesel), to simulate and calculate the total cost $[12,23,26]$.

\subsection{HOMER}

HOMER (Hybrid Optimization Model for Electric Renewables) is the most commonly used software. It has developed by the National Renewable Energy Laboratory (USA). It is designed for both on- and off-grid systems and it is appropriate for carrying out fast pre-feasibility, optimization, and sensitivity analysis in multiple possible system configurations. HOMER has been used extensively 
in the literature for hybrid renewable energy system optimization and different case studies [27, 28]. It will be particularly exploited in this study for comparative purposes.

\section{Hybrid Power Generation System Model}

The aim of modeling is to formulate a general model to evaluate the total investment depending on the location, renewable resources opportunities, and the load demand. For this purpose a macroscopic modeling of a stand-alone hybrid power generation system consisting of wind turbine generator (WTG), photovoltaic (PV) panels, tidal turbine generators (TTG) and storage batteries (SB) and other devices to feed a load demand is presented.

\subsection{Wind Turbine Model}

The wind turbine extracted obtained power depends on the power curve given by the manufacturer and also on the height of turbine $h$, and the roughness of the land surface. The available power at the front end of the wind energy conversion system is expressed by Eq. (1)

$$
P_{w}=\frac{1}{2} \times \rho \times C_{\mathrm{p}} \times \pi \times R^{2} \times v^{3} \times \eta_{w}
$$

where $\eta_{w}$ is the wind turbine efficiency (assumed to be $90 \%$ in this study), $R$ is the blades radius, $\rho$ is the air density, $C_{\mathrm{p}}$ the power coefficient, and $v$ is the wind speed. The relationship between available output power $P_{w}(t)$ and wind speed can be approximated by Eq. (2).

$$
P_{w}= \begin{cases}0 ; & v<v_{\text {cutin }}, v>v_{\text {cutout }} \\ P_{w \max } \times \frac{v-v_{\text {cutin }}}{v_{\text {rated }}-v_{\text {cutin }} ;} ; & v_{\text {cutin }}<v<v_{\text {rated }} \\ P_{w \max } ; & v_{\text {rated }} \leq v \leq v_{\text {cutout }}\end{cases}
$$

Table 1 Wind turbine parameters

\begin{tabular}{l|l}
\hline Cut-in speed, $v_{\text {cutin }}$ & $5 \mathrm{~m} / \mathrm{s}$ \\
\hline Cut-out speed, $v_{\text {cutout }}$ & $25 \mathrm{~m} / \mathrm{s}$ \\
\hline Rated speed, $v$ & $15 \mathrm{~m} / \mathrm{s}$ \\
\hline The maximum output power, $P_{w \max }$ & $2300 \mathrm{~kW}$ \\
\hline Swept area & $3959 \mathrm{~m}^{2}$ \\
\hline Number of blades & 3 \\
\hline Rotor diameter & $71 \mathrm{~m}$ \\
\hline Hub height & $57 / 64 / 85 / 98 / 113 \mathrm{~m}$ \\
\hline
\end{tabular}


where $P_{w \max }$ is the maximum output power. $v, v_{\text {cutin }}, v_{\text {rated }}, v_{\text {cutout }}$ are the wind turbine cut-in, cut-out, and rated speed, respectively. The ENERCON E-70 wind turbine is used. Some of its parameters are described in Table 1 [29-32].

The height of the wind turbine tower is a very important factor significantly influencing the operating performance of the turbine. It may also be more than half of the wind turbine system cost. To adjust the measured wind speed to the hub height, Eq. (3) is used.

$$
v(t)=v_{r}(t) \cdot\left(\frac{h}{h_{\mathrm{r}}}\right)^{\gamma}
$$

where $v$ is the wind speed at the desired height $h, v_{r}$ is the wind speed measured at a known reference height $h_{\mathrm{r}}$, the power law exponent $\gamma$ is a factor that depends on the roughness of the terrain. For this study this factor is set $0.2[27,33]$.

Figure 5 illustrates wind speeds of the considered island and wind turbine power production at different hub heights.

\subsection{Photovoltaic Array Model}

The output power of a PV module depends on the surface of semiconductors exposed to solar radiation, the tiled surfaces of the PV module, the ambient temperature, and the characteristics of the PV cells under industrial standard test conditions of solar radiation [34]. The output power $P_{\mathrm{pv}}$ can therefore be calculated by Eq. (4) [35, 36].
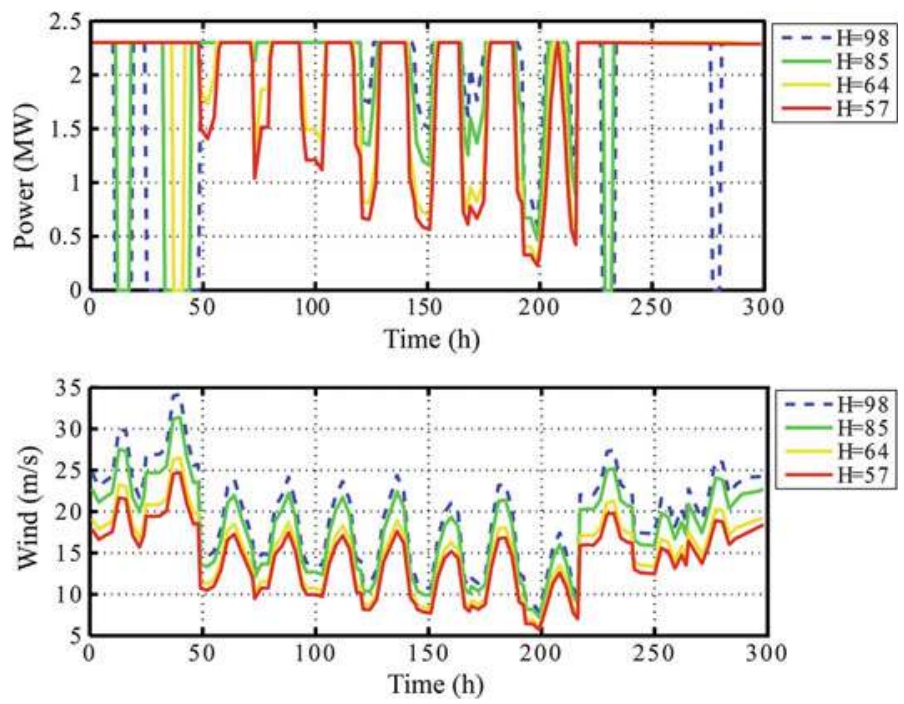

Fig. 5 Wind speed and power production at different hub heights 


$$
P_{\mathrm{pv}}=N_{\mathrm{pv}} \times \eta_{\mathrm{pv}} \times A_{m} \times G_{t}
$$

where $\eta_{\mathrm{pv}}$ is the instantaneous PV module generator efficiency, $N_{\mathrm{pv}}$ is the number of modules, $A_{m}$ is the area of a single module used in a system and $G_{t}$ is the global incident irradiance on the titled plane. In this analysis, each PV module has a rated power of $285 \mathrm{~W}$.

Figure 6 illustrates monthly solar radiation close to the considered island and the generated power in one PV module.

\subsection{Tidal Current Turbine Model}

The output power of a tidal current turbine system $P_{\text {tid }}$ has a similar dependence as a wind turbine and is expressed by Eq. (5).

$$
P_{\text {tid }}=\frac{1}{2} \times N_{\text {tid }} \times \eta_{\text {tid }} \times C_{\mathrm{p}}(\beta, \lambda) \times \rho_{t} \times A \times V^{3}
$$

where $N_{\text {tid }}$ the total number of current turbines, $\eta_{\text {tid }}$ is the efficiency of the tidal turbine is selected according to tidal current characteristics, $\rho_{t}$ is the seawater density, $A$ is the cross sectional area of the tidal turbine rotor, $V$ is the tidal current velocity, $C_{\mathrm{p}}$ is the turbine power coefficient and is estimated to be in the range of $(0.35-0.5)[37,38]$. For the considered system, the pitch has a fixed value, thus, the power coefficient depends only on the tip speed ratio $\lambda$, defined by Eq. (6).
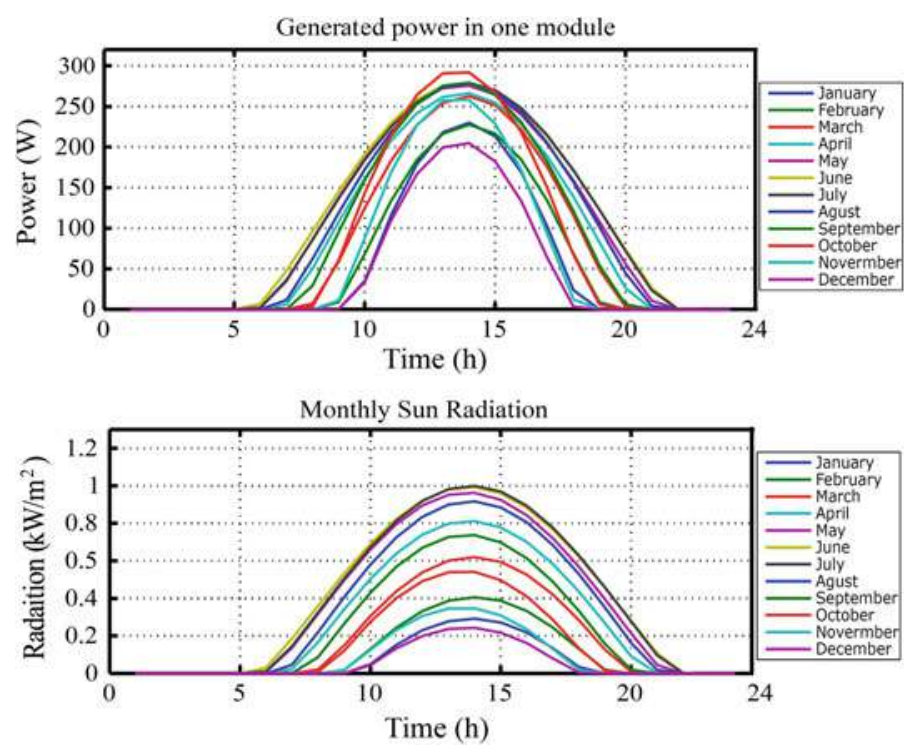

Fig. 6 Monthly solar radiation input data with power production 


$$
\left\{\begin{array}{l}
\lambda=\frac{R_{h} \times \omega_{h}}{v_{h}} \\
\lambda_{i h}=\frac{1}{\frac{1}{\lambda}-0.003} \\
C_{\mathrm{p}}(\lambda)=0.73 \times\left(\frac{151}{\lambda_{\text {ih }}}-13.2\right) \times \mathrm{e}^{-\frac{18.4}{\lambda_{\text {ih }}}}
\end{array}\right.
$$

where $R_{h}$ is the tidal turbine rotor radius and $\omega_{h}$ is the rotor mechanical rotational speed. The maximum $C_{\mathrm{p}}$ value is 0.44 , which corresponds to a tip speed ratio of 7.59. This value is considered as the optimal one $\left(\lambda_{\text {opt }}\right)$ to achieve maximum power point tracking (MPPT) under rated tidal current speeds. The turbine maximum speed to follow (MPPT) is $25 \mathrm{rpm}(2.1 \mathrm{rad} / \mathrm{s})$ for a tidal current of $2.25 \mathrm{~m} / \mathrm{s}$. When the marine current exceeds $2.25 \mathrm{~m} / \mathrm{s}$, the extracted power will be limited by control strategies. The extracted power for different tidal current speeds is calculated by (5). A typical $500 \mathrm{~kW}$ direct-driven turbine is considered and the corresponding characteristics described in Table 2 [39]. Figure 7 illustrates typical tidal speed near the considered island and power generated by one marine turbine.

Table 2 Tidal turbine parameters

\begin{tabular}{l|l|l}
\hline Cut-in tidal speed & $v_{\text {cutintid }}$ & $<1(\mathrm{~m} / \mathrm{s})$ \\
\hline Rated tidal speed & $v_{\text {ratedtid }}$ & $2.25 \mathrm{~m} / \mathrm{s}$ \\
\hline Cross-sectional area of turbine & $A$ & $201.06 \mathrm{~m}^{2}$ \\
\hline Power coefficient & $C_{\mathrm{p}}$ & 0.44 \\
\hline Cut-out tidal speed & $v_{\text {cutoutid }}$ & $>5 \mathrm{~m} / \mathrm{s}$ \\
\hline
\end{tabular}
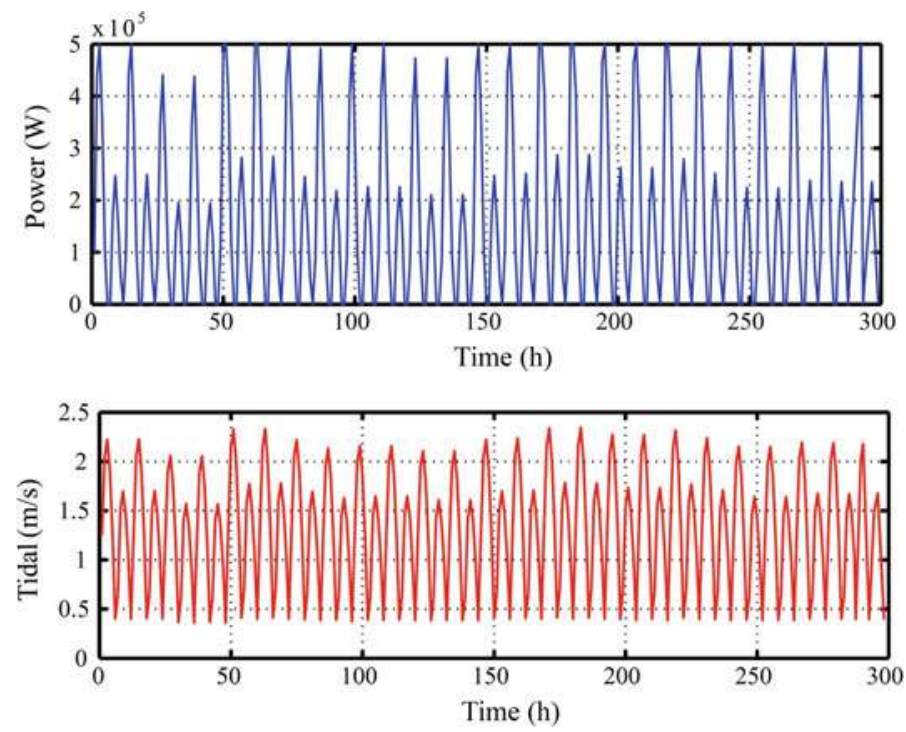

Fig. 7 Tidal speed and power production by one turbine 


\subsection{Storage Batteries Model}

Storage batteries are used to store the energy surplus generated by the hybrid power generation system. They are also used to supply the load during low generation or deficit period. The battery state is related to the previous state of charge and to the system energy flow from $t-\Delta t$ to $t$. The battery capacity mainly depends on the load energy during the day and the period required for supplying the load from the battery bank in case of energy deficit. In all cases, the storage battery capacity (state of charge) is subject to the following constraint as shown in Eq. (7).

$$
\mathrm{SOC}_{\min } \leq \mathrm{SOC}_{t} \leq \mathrm{SOC}_{\max }
$$

where $\operatorname{SOC}(t)$ is the state of charge at time $t, \mathrm{SOC}_{\min }$ is the minimum value of battery state of charge, $\mathrm{SOC}_{\max }$ is the maximum value of battery state of charge. The battery SOC can be considered as the balance between the powers absorbed and generated every hour. The power generated by the hybrid power generation system $\mathrm{PGH}_{t}$, at any time $t$, can be expressed using Eq. (8).

$$
\mathrm{PGH}_{t}=P_{\mathrm{pv}_{t}}+P_{w_{t}}+P_{\text {tid }_{t}}
$$

Energy from batteries is required when the power generated by hybrid renewable system is unable to satisfy the load demand during time $t$. Furthermore, the energy is stored in the batteries whenever the supply from tidal turbine, wind turbines or $P V$ panels exceeds the load demand. At any time, the state of charge of batteries $\mathrm{SOC}_{t}$ is related to the previous state of charge $\mathrm{SOC}_{t-\Delta t}$ and the energy flow between batteries and other sources during time lapse from $t-\Delta t$ to $t$. Therefore two cases are considered in expressing the energy stored in the batteries at time $t$.

- Case 1: During charging, if the total output by other sources exceeds the load demand, the $\mathrm{SOC}_{t}$ is given by Eq. (9).

$$
\mathrm{SOC}_{t}=\mathrm{SOC}_{t-\Delta t}+\left(\mathrm{PGH}_{t}-\mathrm{PL}_{t}\right)
$$

- Case 2: When the load demand is equal or greater than the available generated power, the batteries will then be discharged to cover this deficit, and the $\mathrm{SOC}_{t}$ will be given by Eq. (10).

$$
\mathrm{SOC}_{t}=\mathrm{SOC}_{t-\Delta t}-\left(\mathrm{PGH}_{t}-\mathrm{PL}_{t}\right)
$$

The $\mathrm{SOC}_{\max }$ is 1 , and the $\mathrm{SOC}_{\min }$ is determined as expressed in Eq. (11).

$$
\mathrm{SOC}_{\min }=1-\mathrm{DOD}
$$

where DOD is the depth of discharge. As its maximum is considered $80 \%, \mathrm{SOC}_{\min }$ is $20 \%$. 


\subsection{Load Model}

The number of electric power sources of the hybrid renewable system is determined by the electric load demand. The load profile of the considered island remote site is given in Fig. 4. The maximum load demand is $16 \mathrm{GWh} /$ year with a pick demand of 2 MW, which usually happens in January.

\subsection{Reliability Index}

The concept of reliability index is extremely broad. It covers the system ability to satisfy the load requirement. There are several indicators in the reliability evaluation of a hybrid power generation system. Those indicators are the Loss of Load Expected (LOLE), the Loss of Energy Expected (LOEE) or the Expected Energy Not Supplied (EENS), the Loss of Power Supply Probability (LPSP), and the Equivalent Loss Factor (ELF). In this study, the ELF is considered in evaluating the proposed topology reliability. At each year time step, it should be calculated using Eq. (12).

$$
\mathrm{ELF}=\frac{1}{H} \sum_{h=1}^{H} \frac{Q(h)}{D(h)}
$$

where is $H$, is the total number of step time, $D(h)$ is the total energy demand, $Q(h)$ is the loss of load. The ELF contains information about both the number of outages and their magnitude, and in most cases it should be less than 0.01 [1].

\section{Optimal Sizing Strategies}

The most used strategies to size and design a hybrid power generation system based on renewable aim to select the optimal number of renewable energies converters, such as WTG, PV panels, TTG, and SB. Optimal sizing is achieved according to: (1) Renewables resources availability; (2) Equipment's costs and O\&M services; (3) Maximum energy capacity for the load. It should be mentioned that a previous study has already dealt with a comparison of some optimal sizing approaches of hybrid renewable energy systems [10].

\subsection{Cascade Algorithm}

This algorithm is an optimized linear programming based on a cascade calculation. First, the main renewable energy source device feeds the main electric load, therefore calculating it optimal. After that, the energy shortfall is considered as a 
(a)
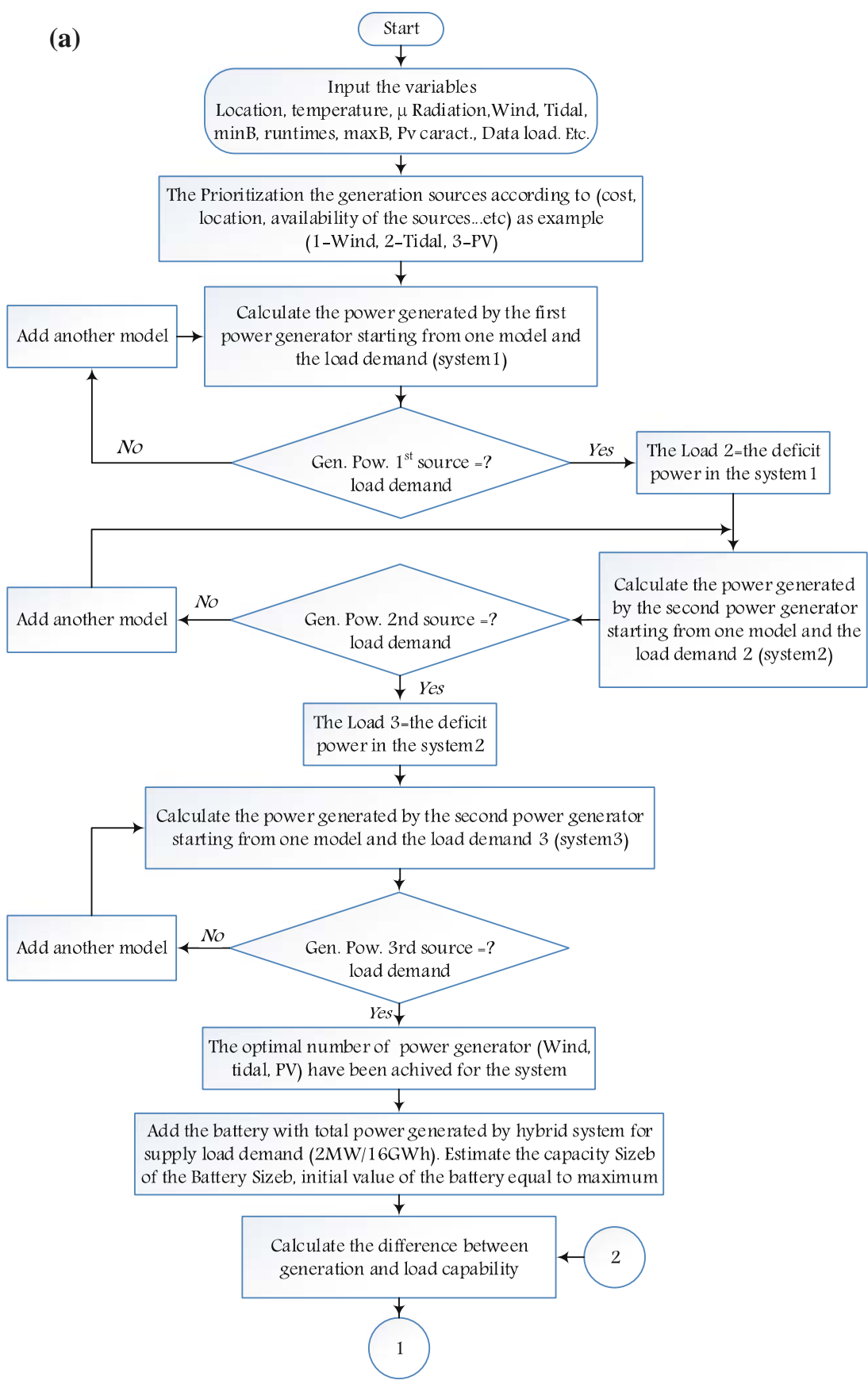

Fig. 8 Flowchart of the cascade algorithm 


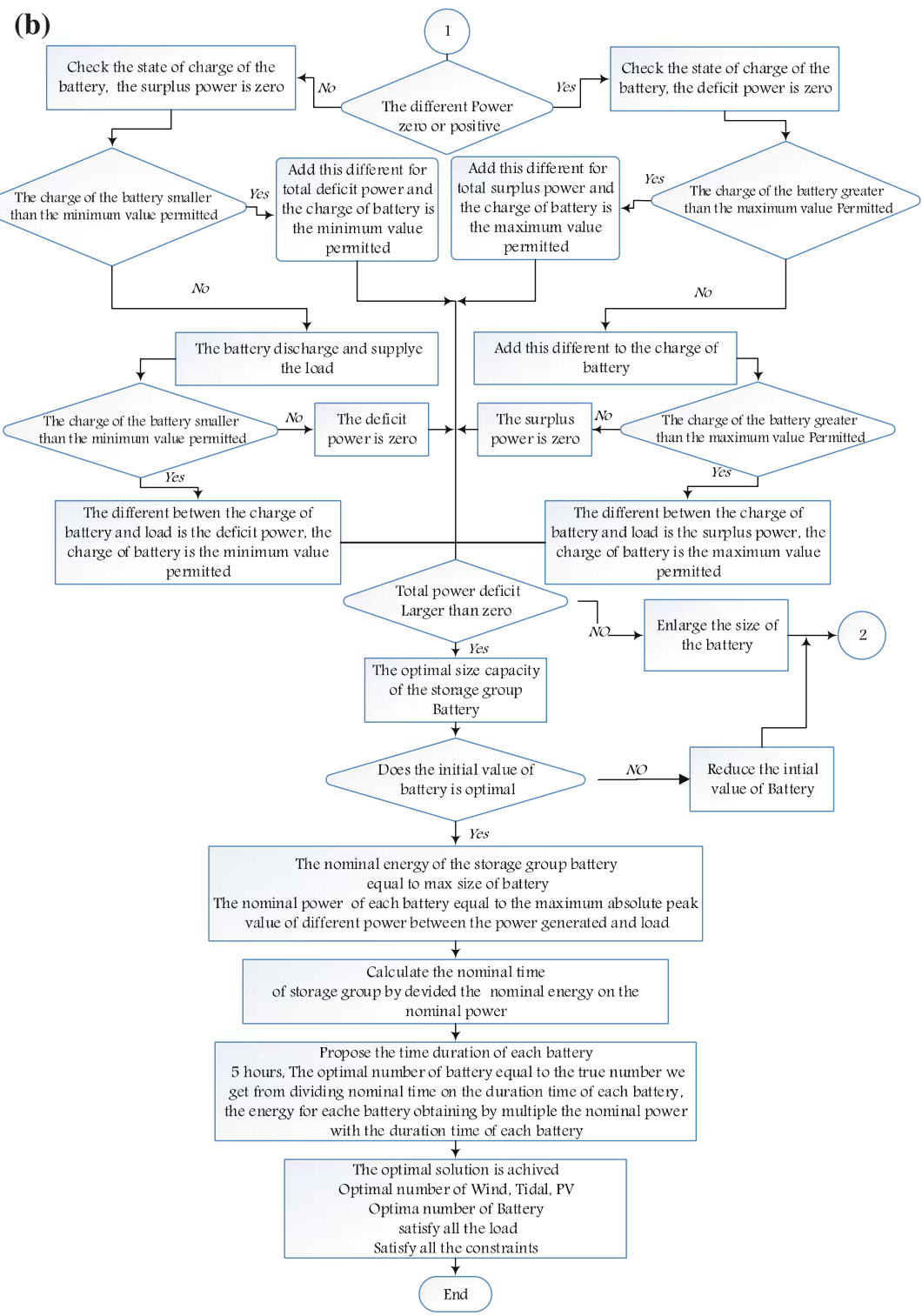

Fig. 8 (continued)

load demand for the consecutive renewable energy source (for optimal number of power generators devices), and so on for the next renewable energy source device as illustrated by the flowchart of Fig. 8 .

Conducting energy balance calculations and ensuring high reliability of the system develop this approach. It also maintains the battery SOC between the minimum and 
maximum values and ensures that this value remains equal or greater than the initial value of SOC the battery at the beginning of the year. It simulates different scenarios to obtain the optimal number of renewable sources available (wind, solar, tidal, and battery) for supplying the load considering a minimum cost, satisfying constraints such as the battery state of charge, limited operation times, and the assumption that no interruption in power supply occurs with a system reliability of $100 \%$. To assess these algorithm different scenarios were carried out as follow.

- Scenario 1: One of the available sources, wind, tidal, or PV is considered with battery regardless the system operating hours.

- Scenario 2: It is the same as scenario 1 except of taking into consideration the determinant daily WTG and TTG working times. This scenario is used in a case of presence of residential areas close to the hybrid power generation system. This allows reducing the noise caused by wind turbine blades rotation.

- Scenario 3: In this case, more than one renewable resource is available. The daily working time is also considered. In this scenario, a particular attention is paid to the priority order of renewable resources. The user selects the first renewable resource, and the algorithm determines its optimal number and reuses it as an entry of the cascade calculation.

\subsection{Cascade Algorithm Optimization Results}

The cascaded algorithm is implemented and applied to design and to optimally size the hybrid power generation feeding Ouessant Island (AC load-2 MW, $16 \mathrm{GWh}$ /year). Simulation input data consists in the annual wind speed profile, the annual tidal current speed profile, and the hourly data of the solar radiation. The estimated power production for each resource is illustrated in Figs. 5, 6, and 7 [40].

For scenario 1, a stand-alone system is considered including only one renewable resource wind, or tidal, or PV with storage batteries system, and with full-time operating hours. Results of the sizing of each component are detailed in Table 3. For this case, Fig. 9a depicts the difference between the total generated power and the load demand, the total generated energy, and the storage batteries energy variations for one year. For scenario 2, the stand-alone hybrid power generation system also includes only one renewable resource wind, or tidal, or PV with a storage batteries system, and a constraint of reduced operation working time. Sizing results are presented in Table $3 \mathrm{~B}$. Figure $9 \mathrm{~b}$ illustrates the difference between the generated power and load demand, the total generated energy, and the storage batteries energy variations for one year. For Scenario 3, it is assumed that more than one renewable resource is available. The hybrid power generation system can be a collection of WTG, TTG, PV panels, and a storage batteries system. The constraints of renewable resource priority order and the reduced operation working time are also imposed. Sizing results are given in Table $3 \mathrm{C}$, while the difference 
Table 3 Optimal hybrid power generation system configurations

\begin{tabular}{|c|c|c|c|c|c|c|}
\hline$N_{\text {wind }}$ & $N_{\text {tidal }}$ & $N_{\mathrm{pv}}$ & \multicolumn{2}{|c|}{ Number and sizes of batteries } & Initial SOC $\%$ & Final SOC $\%$ \\
\hline \multicolumn{7}{|c|}{ A: Scenario 1} \\
\hline \multirow[t]{2}{*}{1} & \multirow[t]{2}{*}{0} & \multirow[t]{2}{*}{0} & 3 & 1.024 MW, 5.120 MWh & \multirow[t]{2}{*}{22} & \multirow[t]{2}{*}{85} \\
\hline & & & 9 & $340 \mathrm{~kW}, 1.71 \mathrm{MWh}$ & & \\
\hline \multirow[t]{2}{*}{0} & \multirow[t]{2}{*}{9} & \multirow[t]{2}{*}{0} & 6 & $3 \mathrm{MW}, 15 \mathrm{MWh}$ & \multirow[t]{2}{*}{53} & \multirow[t]{2}{*}{58} \\
\hline & & & 18 & 1.0 MW, 5.0 MWh & & \\
\hline \multirow[t]{2}{*}{0} & \multirow[t]{2}{*}{0} & \multirow[t]{2}{*}{16,743} & 10 & $3.35 \mathrm{MW}, 16.7 \mathrm{MWh}$ & \multirow[t]{2}{*}{53.8} & \multirow[t]{2}{*}{55} \\
\hline & & & 30 & $1.12 \mathrm{MW}, 5.58 \mathrm{MWh}$ & & \\
\hline \multicolumn{7}{|c|}{ B: Scenario 2} \\
\hline \multirow[t]{2}{*}{3} & \multirow[t]{2}{*}{0} & \multirow[t]{2}{*}{0} & 3 & 4.92 MW, 24.6 MWh & \multirow[t]{2}{*}{51} & \multirow[t]{2}{*}{55} \\
\hline & & & 9 & $1.64 \mathrm{MW}, 8.2 \mathrm{MWh}$ & & \\
\hline \multirow[t]{2}{*}{0} & \multirow[t]{2}{*}{10} & \multirow[t]{2}{*}{0} & 4 & 3.44 MW, 17.2 MWh & \multirow[t]{2}{*}{53} & \multirow[t]{2}{*}{58} \\
\hline & & & 12 & $1.15 \mathrm{MW}, 5.73 \mathrm{MWh}$ & & \\
\hline \multicolumn{7}{|c|}{ C: Scenario 3} \\
\hline \multirow[t]{2}{*}{3} & \multirow[t]{2}{*}{4} & \multirow[t]{2}{*}{5829} & 1 & 9.3 MW, 46.5 MWh & \multirow[t]{2}{*}{40} & \multirow[t]{2}{*}{42} \\
\hline & & & 3 & 3.1 MW, 15.5 MWh & & \\
\hline
\end{tabular}

between the total generated power and load demand, the total generated energy, and the storage batteries energy variations are illustrated in Fig. 9c for one year.

\subsection{Genetic Algorithm}

A genetic algorithm (GA) represents a heuristic search strategy based on the evolutionary ideas of natural selection, and genetics as crossing and mutation. GAs are usually used to solve optimization problems by exploitation random searches with many possible solutions in parallel and uses GA operators instead of deterministic ones. A GA does not need other auxiliary knowledge, except fitness functions or objective function. It is being able to find the global optimal solution that is difficult to approach with other techniques in multidimensional search area [41]. In this study, GAs are applied to searches for configurations of wind turbines, tidal turbines, PV panels, and storages batteries that minimize the hybrid system TNPC with respect to all constraints. Figure 10 depicts the flowchart of genetic algorithm-based optimization.

In this algorithm, in the first step, a set of initial populations (chromosomes) is randomly generated from the ranges of possible solutions. Each chromosome is configured and controlled in order to be an optimal solution for the hybrid power system. The choice of the best chromosome representation in genetic algorithms depends upon the variables of the optimization problem being solved, where the chromosome is a combination of vector of variables and each gene represents one component parameters of the renewable system and must be an optimum number as shown in Fig. 11. Then the fitness function is evaluated for each chromosome, 
Fig. 9 Optimal sizing results of the hybrid power generation systems

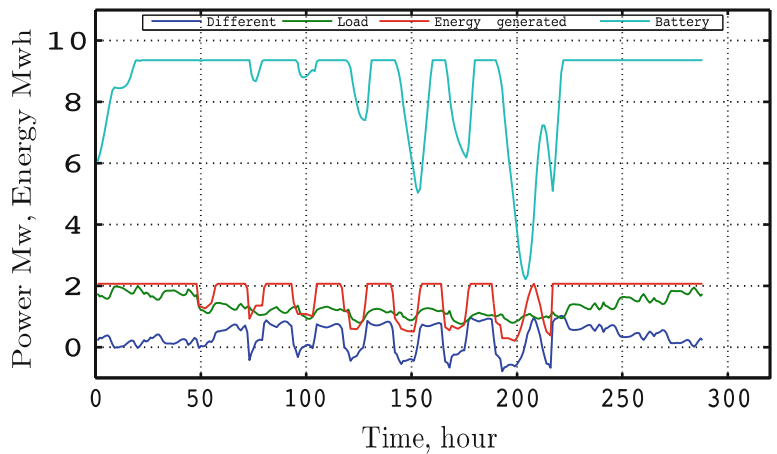

(a) Scenario 1 .

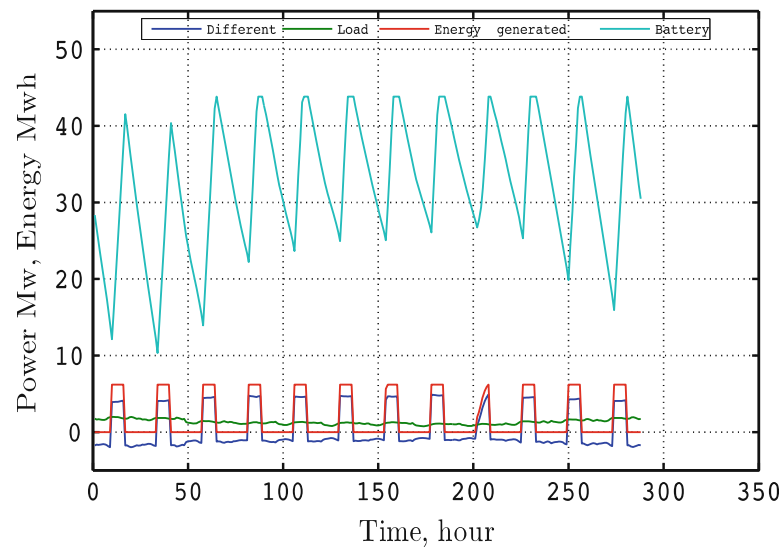

(b) Scenario 2.

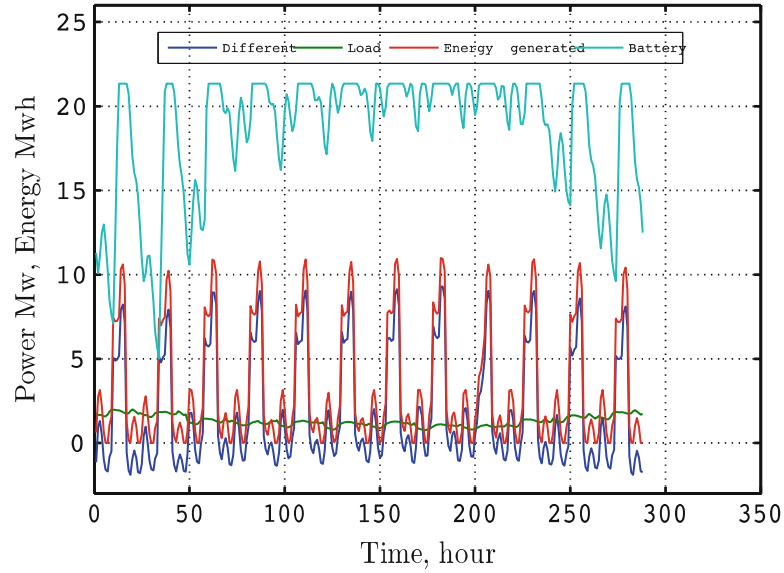

(c) Scenario 3. 


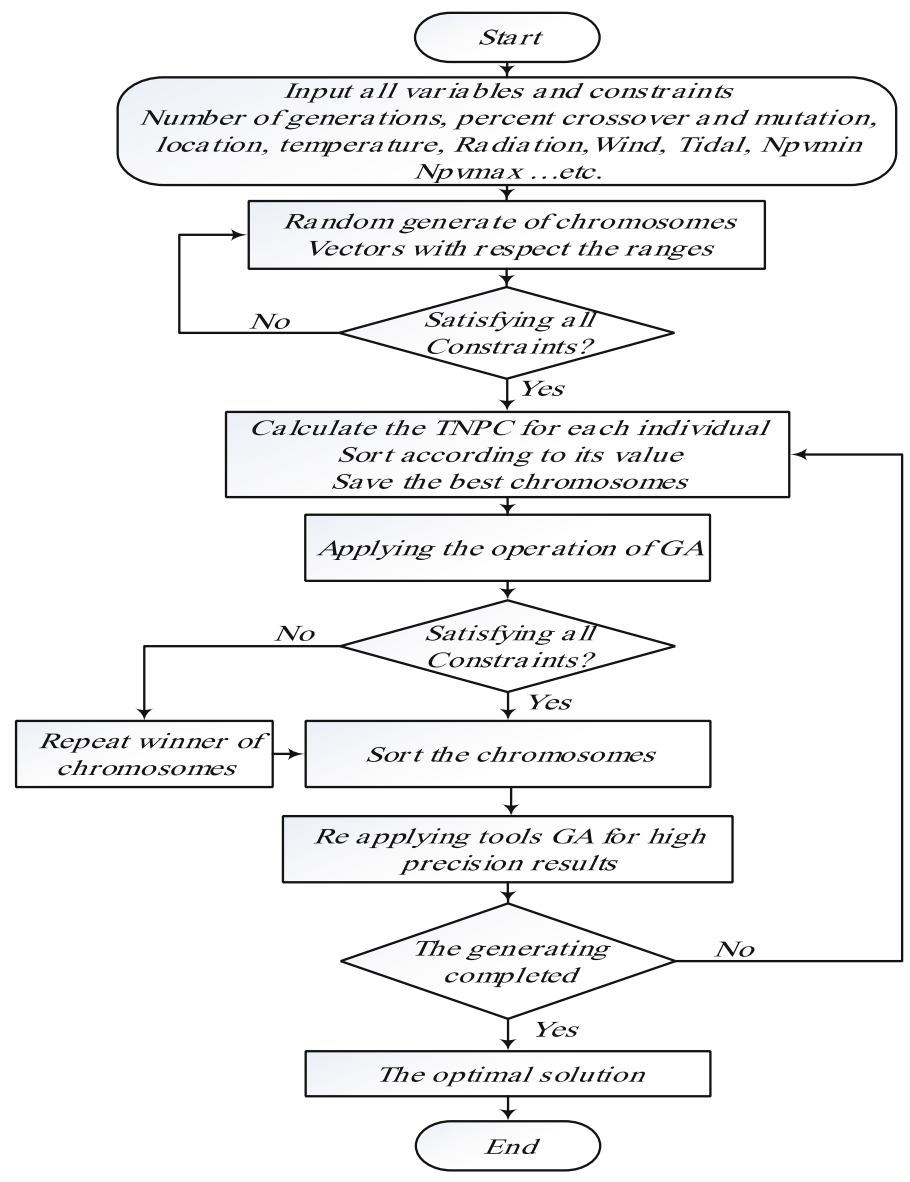

Fig. 10 Flowchart of genetic algorithm-based optimization

where chromosomes that meet all the constraints are selected and arranged according to values from the best to the worst, while others are ignored, as they do not meet constraints. After that, main operations of the genetic algorithms are applied to chromosomes. They consist in selection, crossover, and mutation, at each time. New generations are evaluated and sorted in order of preference, ensuring that restrictions were investigated, keeping best chromosomes in every generation.

In this work, at the first generation, random 100 chromosomes were generated according to ranges of each component. Dividing the chromosomes equally into two groups of parents in each time performs the crossover operation. Application of the crossover process between 1st parent $(n)$ with 2 nd parent $(n+50)$ is random and depends on the probability of crossover $P_{\mathrm{c}}$. Before performing crossover, a single random crossover point on both parents chromosome strings (hybrid components) is selected. 


\section{Parents}

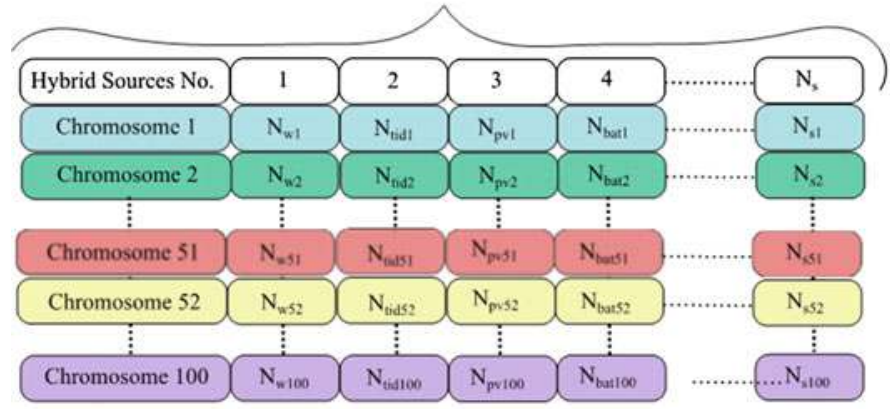

Children after the Crossover

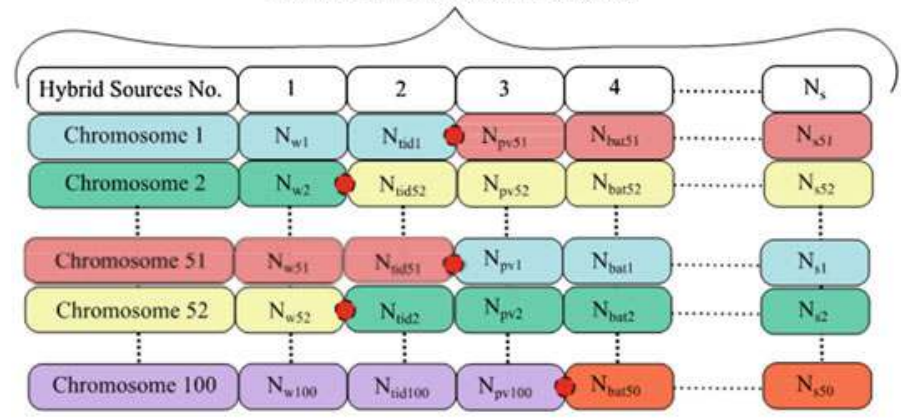

\section{Children after the Mutation}

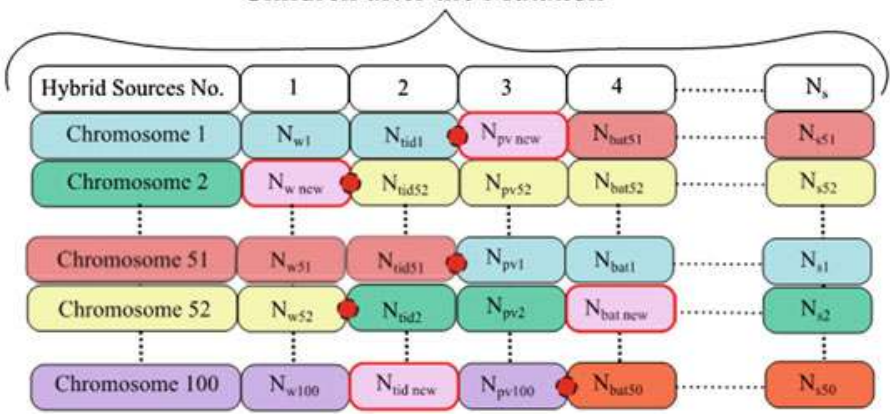

Fig. 11 Hybrid energy systems codification in chromosomes for one generation

All data beyond that point in either chromosome string is swapped between the two parent chromosomes. The resulting chromosome represents new children. As example, for a crossover between two parents when the randomized crossover point is 2 , we can see the following new children.

\begin{tabular}{l|l|l|l|l}
\hline Parent1 & $N_{\text {wind1 }}$ & $N_{\text {tid1 }}$ & $N_{\text {pv1 }}$ & $N_{\text {bat1 }}$ \\
\hline Parent2 & $N_{\text {wind51 }}$ & $N_{\text {tid51 }}$ & $N_{\text {pv51 }}$ & $N_{\text {bat51 }}$ \\
\hline
\end{tabular}




\begin{tabular}{l|l|l|l|l}
\hline Child1 & $N_{\text {wind1 }}$ & $N_{\text {tid1 }}$ & $N_{\text {pv51 }}$ & $N_{\text {bat51 }}$ \\
\hline Child2 & $N_{\text {wind51 }}$ & $N_{\text {tid51 }}$ & $N_{\text {pv1 }}$ & $N_{\text {bat1 }}$ \\
\hline
\end{tabular}

The mutation operation depends on the probability called the probability of mutation $P_{\mathrm{m}}$. There are several methods of mutation as the Flip Bit method, the boundary method, the non-uniform method, the uniform method, and finally the Gaussian method. In this work, the uniform mutation operation method has been applied, where the operator replaces the value of the chosen gene to a uniform random value chosen between the user-defined upper and lower bounds for that gene as the following example: The boundary of the components for the new genes are defined as follows:

Wind turbines numbers:

$$
N_{\text {wind }_{\text {min }}} \leq N_{\text {wind }_{\text {new }}} \leq N_{\text {wind }_{\text {max }}}
$$

Tidal turbine numbers:

$$
N_{\text {tid }_{\text {min }}} \leq N_{\text {tid }_{\text {new }}} \leq N_{\text {tid }_{\text {max }}}
$$

PV panels numbers:

$$
N_{\mathrm{pv}_{\text {min }}} \leq N_{\mathrm{pv}_{\text {new }}} \leq N_{\mathrm{pv}_{\text {max }}}
$$

Batteries numbers:

$$
N_{\text {bat }_{\text {min }}} \leq N_{\text {bat }_{\text {new }}} \leq N_{\text {bat }_{\text {max }}}
$$

When mutation is applied in this chromosome in random gene as gene 3 , we can see the new children as follows:

\begin{tabular}{l|l|l|l|l}
\hline Parent1 & $\mathrm{N}_{\text {wind1 }}$ & $\mathrm{N}_{\text {tid1 }}$ & $\mathrm{N}_{\mathrm{pv} 1}$ & $\mathrm{~N}_{\text {bat1 }}$ \\
\hline \multicolumn{5}{|l}{} \\
Child1 & $\mathrm{N}_{\text {wind1 }}$ & $\mathrm{N}_{\text {tid1 }}$ & $\mathrm{N}_{\mathrm{pvn}}$ & $\mathrm{N}_{\text {bat1 }}$ \\
\hline
\end{tabular}

Crossover and mutation processes can also be seen in Fig. 11. It is important to mention that to get to the optimal result, there are 1000 created generations. In each generation there are 100 generated chromosomes. The scattered crossover function is $80 \%$ of the total crossover operation, while the probability proportion of mutation function is $20 \%$ of the mutation operation. The initial applied classical GA algorithm has been improved considering genes within winner chromosomes to accelerate the convergence process to the optimal result. The proposed strategy is able to frequently modify chromosomes, where, over subsequent generations, the population develops toward the optimal solution. While giving flexibility in the 
choice of system components, the economic issue has been taken into account considering the TNPC minimization.

\subsection{Genetic Algorithm Optimization Results}

The classical then the enhanced genetic algorithms have been applied to design and to optimally size the hybrid power generation feeding Ouessant Island (AC load$2 \mathrm{MW}, 16 \mathrm{GWh} /$ year). Table 4 summarizes the optimal sizing results (most recommended chromosomes). The main conclusion that could be drawn from these results is that a hybrid system based on wind and battery seems to be the best compromise in terms of cost (TNPC). Indeed, Bretagne region in France has favorable wind conditions. Conversely, a hybrid system based on PV and battery is clearly not an interesting solution mainly due to the region low temperatures and solar radiation. It is important to mention that the achieved results are almost specific the studied Ouessant Island and could not be generalized. Figures 12 and 13 illustrate the energy management balance in the proposed hybrid power generation for two scenarios.

Table 4 Optimization results using GA algorithm

\begin{tabular}{l|l|r|l|l|l}
\hline$N_{\text {wind }}$ & $N_{\text {tidal }}$ & \multicolumn{1}{|c|}{$N_{\text {pv }}$} & Battery size $(\mathrm{MWh})$ & TNPC $(\mathrm{M} \$)$ & COE $(\$ / \mathrm{MWh})$ \\
\hline 2 & 0 & 0 & 0.59 & 3.48 & 94.2 \\
\hline 1 & 1 & 0 & 7.57 & 4.52 & 122.1 \\
\hline 1 & 1 & 459 & 7.22 & 4.71 & 127.2 \\
\hline 0 & 6 & 0 & 8.94 & 9.80 & 264.7 \\
\hline 0 & 5 & 6819 & 11.17 & 12.33 & 333.1 \\
\hline 0 & 0 & 19,998 & 12.94 & 28.27 & 763.7 \\
\hline
\end{tabular}

Fig. 12 Hybrid system powers variation in a day (scenario 1)

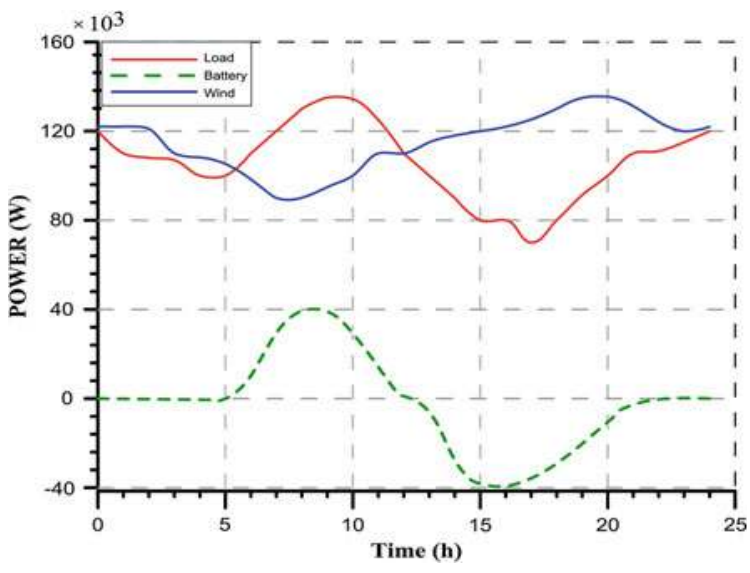


Fig. 13 Hybrid system powers variation in a day (scenario 2)
Fig. 14 Genetic algorithm methods convergence
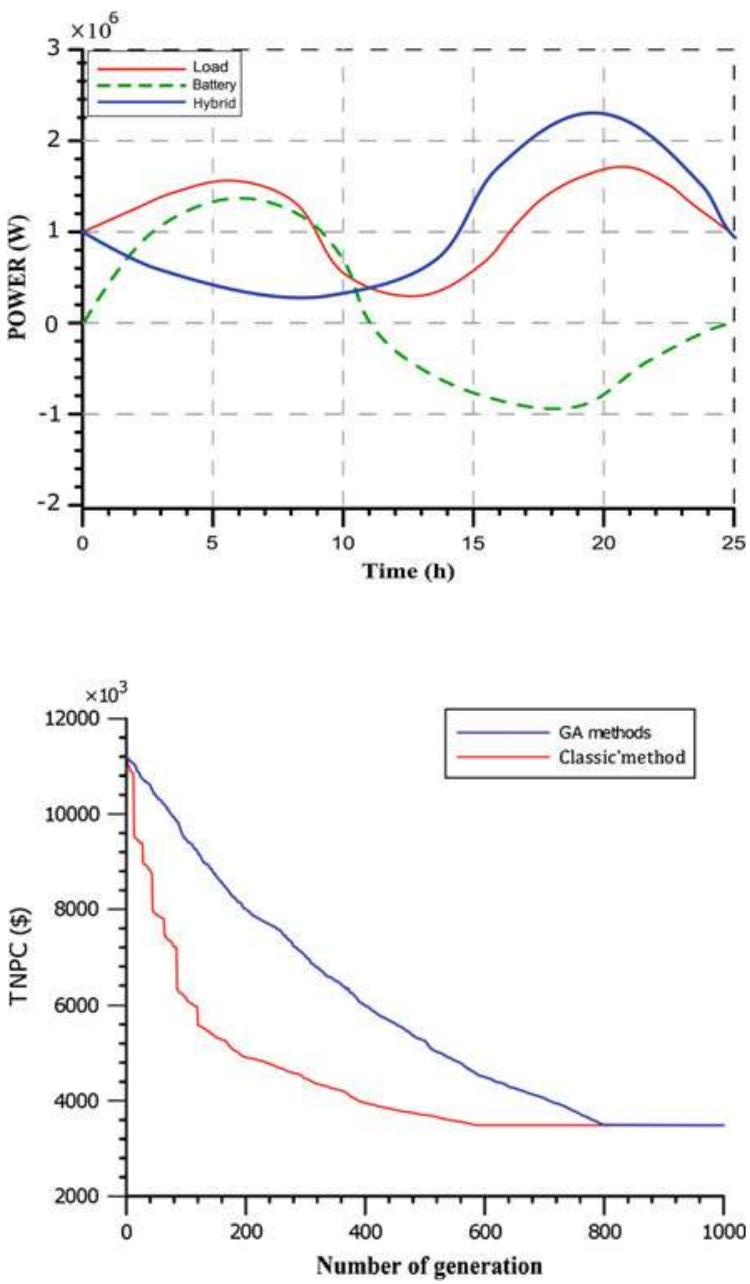

Scenario 1: It represents the optimal system.

Scenario 2: It represents the system that considers all possible components with minimum cost.

It can be observed that the load demand is fully satisfied by the hybrid system in the optimal composition. Figure 14 illustrates the performance of developed enhanced genetic algorithm-based method. The brought convergence improvements are obvious, when achieving the optimal hybrid power generation system. 


\subsection{Particle Swarm Algorithm}

Particle swarm optimization (PSO) is one of the recent techniques based on stochastic optimization [42]. The particle swarm optimization (PSO) algorithm is a member of the wide variety of swarm intelligence methods for solving global optimization issues. PSO is an evolutionary algorithm technique using individual improvement called particles, flying through the problem space plus population cooperation, and competition by following the current optimum particles [43]. In PSO, each individual, referred as a particle, represents a potential solution presumed to have two properties: a position and a velocity. Each particle wanders surrounding in the problem space and remembers the best position (objective function value), which has been already discovered. The fitness value is saved and called $P_{\text {best }}$. The particle swarm optimizer is tracking another best values obtained so far by any particle in the population. The position and velocity of each particle are adjusted according to its own experience and that of its neighbors. When a particle captures all the population as its topological neighbors, the best value is a global best and it is called $G_{\text {best }}$. Let $x_{i}$ denote the position of particle $i$ in the search space as expressed in Eq. (13).

$$
x_{i}=\left[x_{i 1}, x_{i 1}, x_{i 2}, \ldots, x_{i d}, \ldots, x_{i N}\right]
$$

In the $N$-dimensional space, each particle continuously records the best solution it has reached during its flight (best fitness value $P_{\text {best }}$ ). The best previous position of the $i$ th particle is memorized under a vector expressed in Eq. (14).

$$
P_{\text {best } i}=\left[P_{\text {besti1 }}, P_{\text {besti2 }}, \ldots, P_{\text {bestid }}, \ldots, P_{\text {besti }}\right]
$$

where $i=1,2,3, \ldots, N$. The global best $G_{\text {best }}$ refers to the best position, which is ever realized by all the population individuals. The best particle of all the swarm particles is denoted $G_{\text {best } d}$.

The velocity for particle $i$ is represented in Eq. (15).

$$
v_{i}=\left[v_{i 1}, v_{i 1}, v_{i 2}, \ldots, v_{i d}, \ldots, v_{i N}\right]
$$

The velocity and position of each particle can be continuously adjusted based on the current velocity and the distance from $P_{\text {bestid }}$ to $G_{\text {bestd }}$ using Eqs. (6) and (17).

$$
\begin{gathered}
v_{i}(t+1)=w(t) v_{i}(t)+c_{1} r_{1}\left(P_{i}(t)-X_{i}(t)\right)+c_{2} r_{2}(G(t)-X(t)) \\
X_{i}(t+1)=X_{i}(t)+\chi v_{i}(t+1)
\end{gathered}
$$

In the above equations $c_{1}$ and $c_{2}$ are acceleration constants that pulls each particle towards $P_{\text {best }}$ and $G_{\text {best }}$ positions and each equal to 1.0 for almost all applications. $r_{1}$ and $r_{2}$ are random real numbers drawn from $[0,1]$. Thus, the particle flies through potential solutions toward $P_{i}(t)$ and $G(t)$ in a navigated way 
Table 5 Some of PSO parameters

\begin{tabular}{l|l}
\hline$c_{1}$ and $c_{2}$ & 1 \\
\hline$r_{1}$ and $r_{2}$ & Randomly \\
\hline$w$ & Randomly (18) \\
\hline Number of iteration & 100 \\
\hline Number of population & 10 \\
\hline
\end{tabular}

while still exploring new areas by a stochastic mechanism to escape from local optima. Since there was no actual mechanism for controlling the velocity of a particle, it was necessary to impose a maximum value $V_{\max }$, which controls the maximum travel distance in each iteration to avoid this particle flying past good solutions. After updating positions, it must be checked that no particle violates the boundaries of search space. If a particle has violated the boundaries, it will be set at the boundary of search space. $\chi$ is constriction factor, which is used to limit velocity, here $\chi=0.7$ [44-47].

In $(16), w(t)$ refers to inertia coefficient, which indicates the impact of the previous history of velocities on the current iteration one and is extremely important to ensure convergent behavior. There are different strategies to calculate the inertia weight. These calculations depend on the designer that can assume it as fixes or variable $[48,49]$. In this work we have considered the inertia weight as random and it is given by Eq. (18). All the PSO algorithm parameters are summarized in Table 5.

$$
w(t)=0.5+\frac{\operatorname{rand}()}{2}
$$

\subsection{Particle Swarm Optimization Results}

The hybrid power generation system economic optimization is based on an objective function minimizing the COE and the TNPC, besides taking into account other constraints as meet the load demand with high reliability, system optimal sizing, battery SOC, and planning expansion for future development. In this context, Fig. 15 illustrates the flowchart of the proposed PSO optimization methodology.

One of the extremely important tasks in PSO algorithm application is how to design the objective function and the considered constraints in each individual particle.

Initially, random values for position and velocity are created for 10 individual particles in each swarm with respect to the PSO characteristics and all constraints (minimum and maximum of hybrid components, reliability etc.). The maximum iteration number is 100. Then, (16) and position are carried out with other parameters values as data in Table 5. Position and velocity will therefore be updated at each time, safeguarding best values and neglecting the worst ones. The 


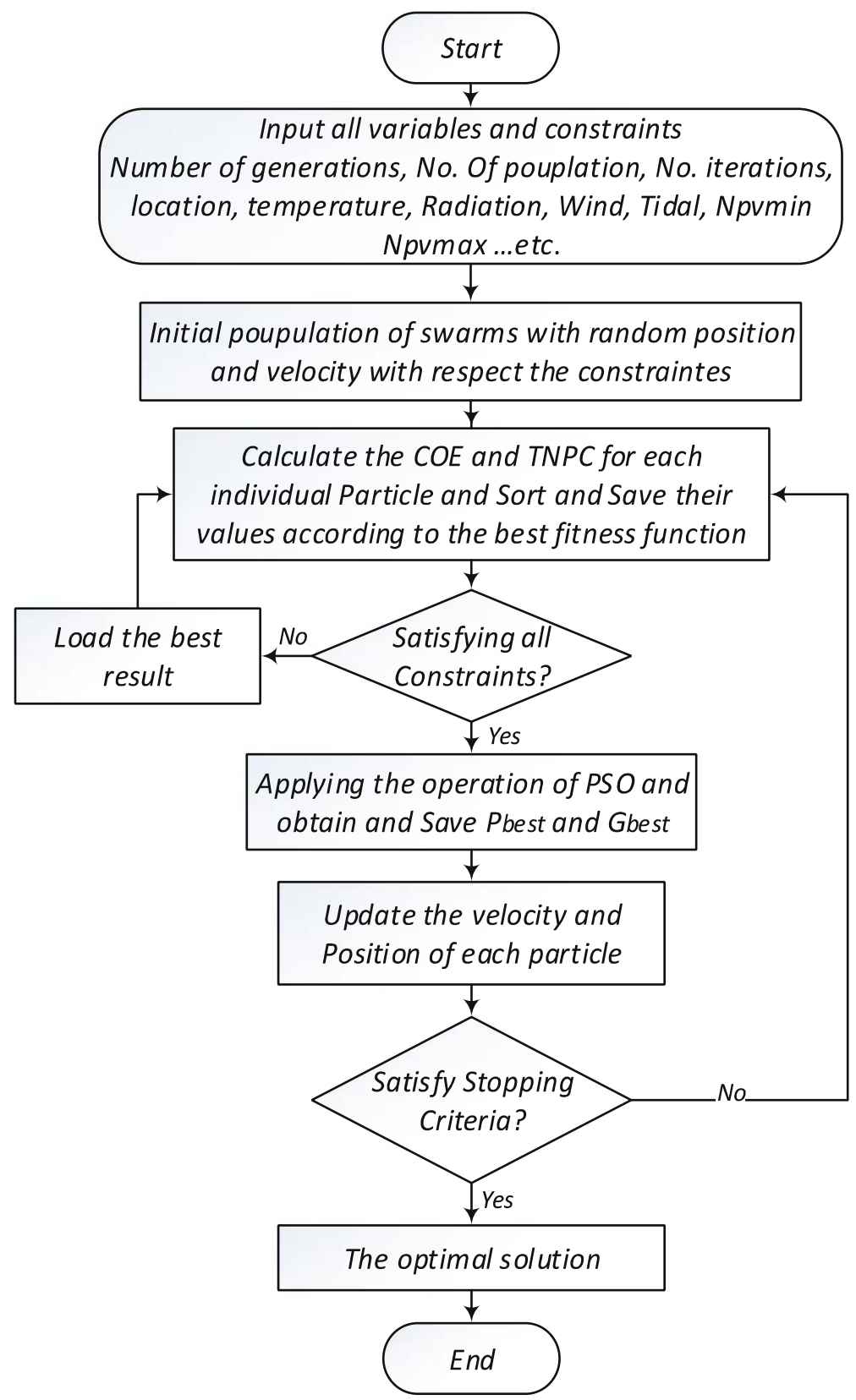

Fig. 15 PSO algorithm flowchart 
search process will be terminated if the number of iterations reaches a final value or if the value of optimal solution reaches the tolerance value, which was considered in this paper equal to 0.0001 . The final optimum solution is delegated to the system designer depending on its experience, development and expansion of a pre-existing system, or creating a new system hybrid system. In this study, The PSO algorithm is implemented to achieve the optimal solution for the different following scenarios and constraints.

Scenario 1: This scenario considers a hybrid renewable system including all the available renewable sources and the batteries to obtain the minimum COE and the lowest TNPC. The achieved optimal result is given in Table 6. The PSO algorithm convergence curve for this scenario is shown in Fig. 16.

Scenario 2: This scenario considers a hybrid renewable system including two renewable sources (wind turbines and PV panels, tidal turbines and PV panels, wind and tidal turbines) with batteries. The achieved optimal results are given in Table 7.

Table 6 Optimization results using PSO algorithm scenario 1

\begin{tabular}{l|l|l|l|l|l}
\hline$N_{\text {wind }}$ & $N_{\text {tidal }}$ & $N_{\mathrm{pv}}$ & Battery size $(\mathrm{MWh})$ & TNPC $(\mathrm{M} \$)$ & COE $(\$ / \mathrm{MWh})$ \\
\hline 2 & 0 & 0 & 5.9 & 3.48 & 94.2 \\
\hline
\end{tabular}

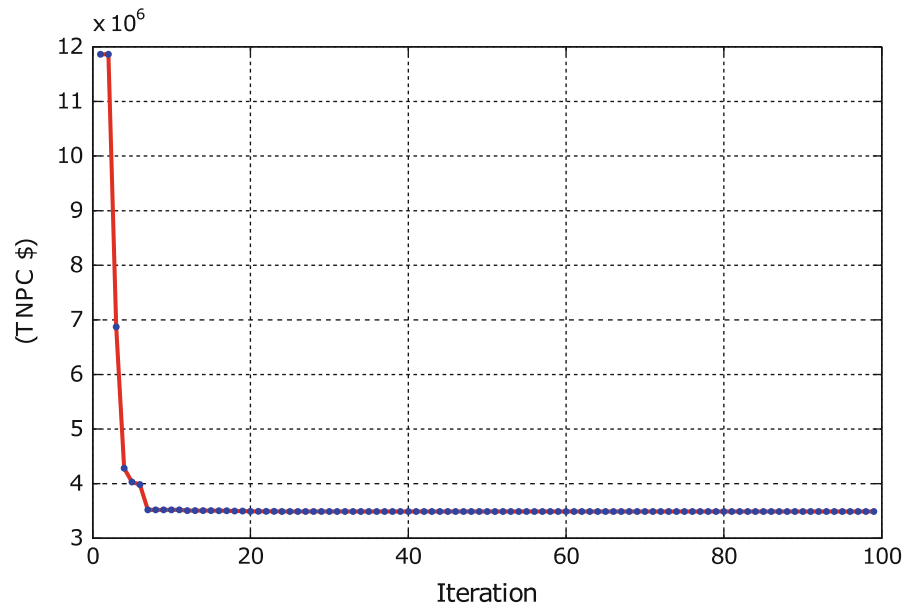

Fig. 16 PSO algorithm convergence for scenario 1

Table 7 Optimization results using PSO algorithm for scenario 2

\begin{tabular}{l|l|l|l|l|l}
\hline$N_{\text {wind }}$ & $N_{\text {tidal }}$ & $N_{\mathrm{pv}}$ & Battery size $(\mathrm{MWh})$ & TNPC $(\mathrm{M} \$)$ & $\mathrm{COE}(\$ / \mathrm{MWh})$ \\
\hline 1 & 0 & 11 & 10.9 & 3.71 & 100.3 \\
\hline 1 & 1 & 0 & 7.5 & 4.52 & 122.1 \\
\hline 0 & 6 & 1 & 8.94 & 9.81 & 264.7 \\
\hline
\end{tabular}


Scenario 3: This scenario considers a hybrid renewable system including one renewable source energy sources (among wind turbines, tidal turbines, and PV panels) with batteries. The achieved optimal results are given in Table 8 .

Scenario 4: This scenario takes into consideration development and expansion of an existing system that has one tidal turbine with possible contribution of all the above-mentioned renewable sources with batteries. The achieved optimal result is given in Table 9.

Scenario 5: This scenario considers a hybrid renewable system including all the available renewable sources and the batteries to obtain the minimum surplus power, the minimum COE, and the lowest TNPC. The achieved optimal result is given in Table 10. The PSO algorithm convergence curve for this scenario is shown in Fig. 17.

Table 8 Optimization results using PSO algorithm for scenario 3

\begin{tabular}{l|l|l|l|l|l}
\hline$N_{\text {wind }}$ & $N_{\text {tidal }}$ & \multicolumn{1}{|l|}{$N_{\mathrm{pv}}$} & Battery size $(\mathrm{MWh})$ & TNPC $(\mathrm{M} \$)$ & COE $(\$ / \mathrm{MWh})$ \\
\hline 0 & 6 & 0 & 8.94 & 9.80 & 264.6 \\
\hline 0 & 0 & 21,862 & 114.5 & 27.28 & 736.8 \\
\hline
\end{tabular}

Table 9 Optimization results using PSO algorithm for scenario 4

\begin{tabular}{l|l|l|l|l|l}
\hline$N_{\text {wind }}$ & $N_{\text {tidal }}$ & $N_{\text {pv }}$ & Battery size $(\mathrm{MWh})$ & TNPC $(\mathrm{M} \$)$ & COE $(\$ / \mathrm{MWh})$ \\
\hline 1 & 1 & 1 & 7.57 & 4.52 & 122.2 \\
\hline
\end{tabular}

Table 10 Optimization results using PSO algorithm for scenario 5

\begin{tabular}{l|l|l|l|l|l}
\hline$N_{\text {wind }}$ & $N_{\text {tidal }}$ & $N_{\mathrm{pv}}$ & Battery size $(\mathrm{MWh})$ & TNPC $(\mathrm{M} \$)$ & COE $(\$ / \mathrm{MWh})$ \\
\hline 1 & 0 & 1313 & 10.17 & 4.27 & 115.4 \\
\hline
\end{tabular}

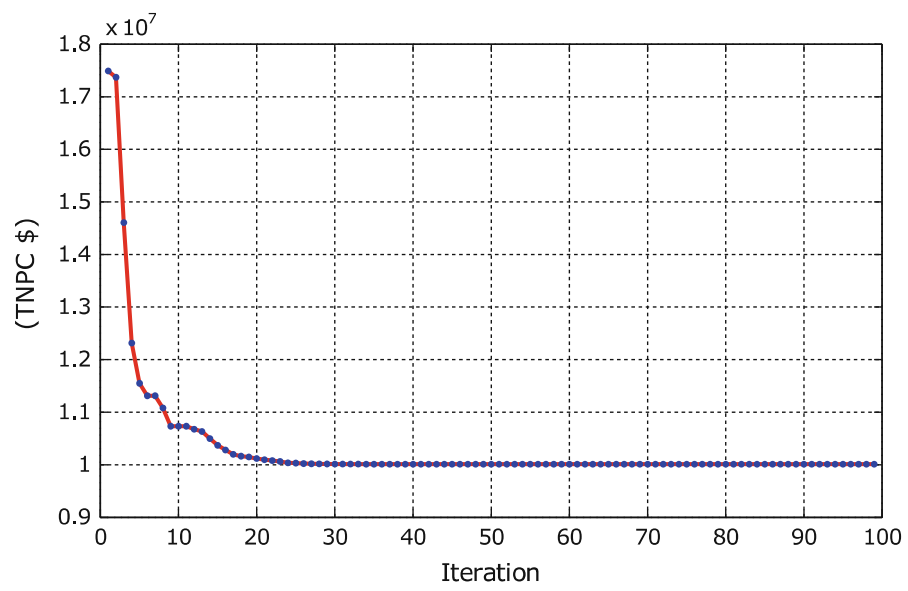

Fig. 17 PSO algorithm convergence for scenario 5 
From all above presented scenarios and achieved results, it can be observed that load demand has been fully satisfied by the hybrid power generation system in the optimal composition. For illustration, Fig. 18 shows the optimal energy management balance in one day for scenario 1, while, Fig. 19 illustrates batteries SOC variation.

As for GAs and for the purpose of accelerating the PSO convergence to the optimal results, the initial classical PSO algorithm has been improved treating now each component size inside one particle.

The same conclusions as for GAs could be drawn from the achieved results illustrated by the above-presented tables. Indeed, a hybrid power generation system based on wind and battery seems to be the best compromise in terms of cost (TNPC).

Fig. 18 Hybrid system powers variation in a day (scenario 1)
Fig. 19 battery SOC variation in a day (scenario 1)
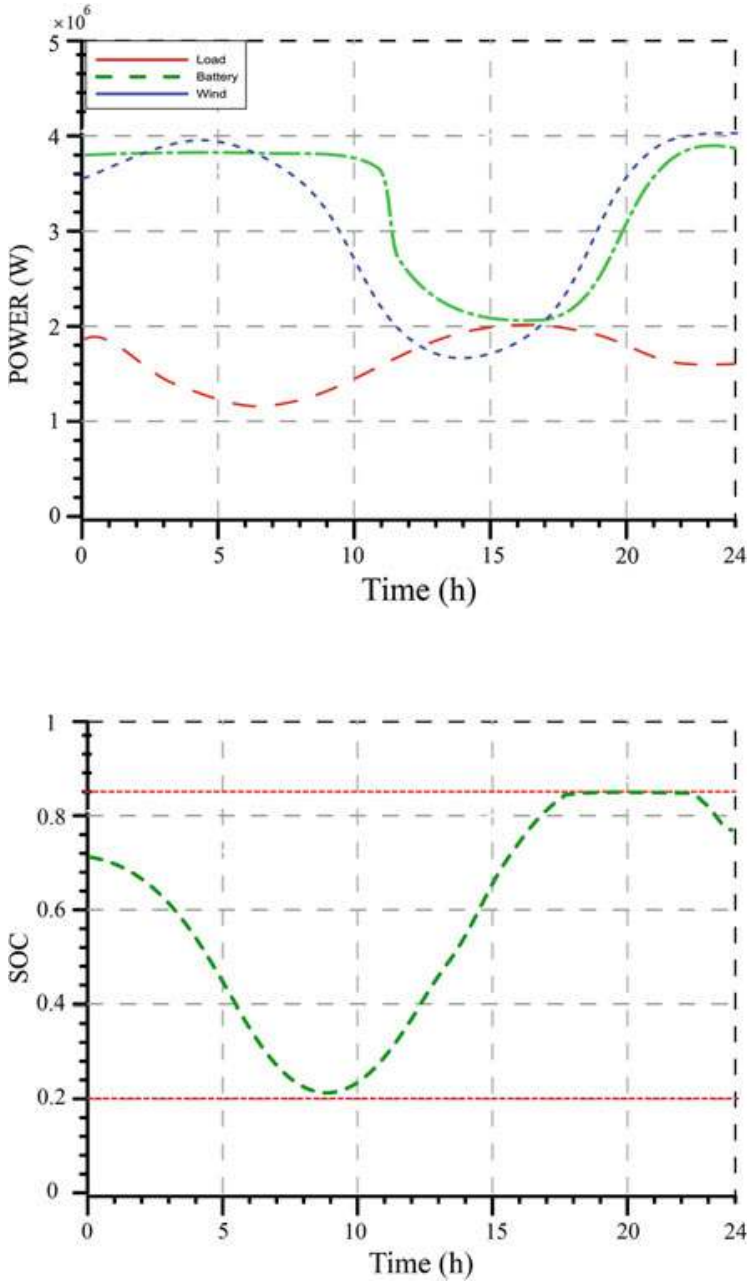
Table 11 Comparison of the proposed optimization approaches

\begin{tabular}{l|l|l|l|l|l|l}
\hline & \multicolumn{3}{|l|}{ Linear approaches } & \multicolumn{4}{l}{ Artificial intelligence approaches } \\
\hline $\begin{array}{l}\text { Optimization } \\
\text { tools/techniques }\end{array}$ & HOMER & Cascade & $\begin{array}{l}\text { Classical } \\
\text { GA }\end{array}$ & $\begin{array}{l}\text { Enhanced } \\
\text { GA }\end{array}$ & $\begin{array}{l}\text { Classical } \\
\text { PSO }\end{array}$ & $\begin{array}{l}\text { Enhanced } \\
\text { PSO }\end{array}$ \\
\hline Accuracy & + & + & + & ++ & ++ & ++++ \\
\hline Calculation time & $8-10 \mathrm{~min}$ & $1-2 \mathrm{~min}$ & $4-6 \mathrm{~h}$ & $2-3 \mathrm{~h}$ & $30-45 \mathrm{~min}$ & $2-3 \mathrm{~min}$ \\
\hline $\begin{array}{l}\text { Control } \\
\text { optimization }\end{array}$ & $\begin{array}{l}\text { Black } \\
\text { Box }\end{array}$ & $\begin{array}{l}\text { Full } \\
\text { control }\end{array}$ & $\begin{array}{l}\text { Full } \\
\text { control }\end{array}$ & $\begin{array}{l}\text { Full } \\
\text { control }\end{array}$ & $\begin{array}{l}\text { Full } \\
\text { control }\end{array}$ & $\begin{array}{l}\text { Full } \\
\text { control }\end{array}$ \\
\hline $\begin{array}{l}\text { Number of } \\
\text { iterations }\end{array}$ & Not available & 1 & $800-1000$ & $400-500$ & $200-250$ & $5-25$ \\
\hline COE $(\$ / M W h)$ & 151 & 149 & 96.2 & 94.2 & 94.2 & 94.2 \\
\hline
\end{tabular}

\section{Summary and Conclusion}

This chapter dealt with a comparative study of three approaches devoted to the optimal sizing of a hybrid power generation system full based on renewables and storage batteries to fulfill the load demand of a remote area in a specific marine context, which the Ouessant Island in the Bretagne region (France). The hybrid system uses the available renewables resources around the island: wind energy, marine energy (tidal current), and PV. The hybrid system has been designed and optimally sized based on economical targets, for different scenarios, that minimizes the COE and the TNPC, in addition to specific constraints.

Three specific optimization approaches have been investigated: (1) Cascaded computation (linear programming approach); (2) Genetic algorithms-based approach; (3) Particle swarm optimization. The achieved optimal results have been also compared to those achieved the well-known commercial software HOMER. Table 11 illustrates this comparison. This table clearly highlights the improvements brought by the proposed and enhanced optimization approaches

\section{References}

1. Mohammed OH, Amirat Y, Benbouzid MEH, Tang T (2013) Hybrid generation systems planning expansion forecast: a critical state of the art review. In: Proceedings of the 39th annual conference of the Industrial Electronics Society, Austria, 10-13 Nov 2013

2. Akella A, Saini R, Sharma MP (2009) Social, economical and environmental impacts of renewable energy systems. Renew Energy 34(2):390-396

3. Erdinc O, Uzunoglu M (2012) Optimum design of hybrid renewable energy systems: overview of different approaches. Renew Sustain Energy Rev 16(3):1412-1425

4. Addo EOK, Asumadu J, Okyere PY (2014) Optimal design of renewable hybrid energy system for a village in Ghana. In: Proceedings of the 9th conference on industrial electronics and applications, Hangzhou, China, 09-11 June 2014

5. Bhandari B et al (2015) Optimization of hybrid renewable energy power systems: A review. Precision Eng Manuf Green Technol 2(1):99-112 
6. Safari M, Sarvi M (2014) Optimal load sharing strategy for a wind/diesel/battery hybrid power system based on imperialist competitive neural network algorithm. IET Renew Power Gener 8(8):937-946

7. Zahboune $\mathrm{H}$ et al (2014) The new electricity system cascade analysis method for optimal sizing of an autonomous hybrid PV/Wind energy system with battery storage. In: 5th IEEE international renewable energy congress, Hammamet, Tunisia, 25-27 Mar 2014

8. Sheng L, Zhou Z, Charpentier JF, Benbouzid MEH (2015) Island power management using a marine current turbine farm and an ocean compressed air energy storage system. In: Proceedings of the European wave and tidal energy conference, Nantes, France, 6-9 Sept 2015

9. Zhou Z, Scuiller F, Charpentier JF, Benbouzid MEH, Tang T (2014) Application of flow battery in marine current turbine system for daily power management. In: Proceedings of the international conference on green energy, Sfax, Tunisia, 25-27 Mar 2014

10. Mohammed OH, Amirat Y, Feld G, Benbouzid MEH (2016) Hybrid generation systems planning expansion forecast state of the art review: optimal design vs technical and economical constraints. Electr Syst (12). http://journal.esrgroups.org/jes/papers/1212:pdf

11. RETScreen: International Empowering Cleaner Energy Decisions (2016). http://www. retscreen.net/ang/home.php

12. Sinha S, Chandel S (2014) Review of software tools for hybrid renewable energy systems. Renew Sustain Energy Rev 32:192-205

13. Islam FR, Mamun KA (2016) Opportunities and challenges of implementing renewable energy in Fiji Islands. In: Australasian Universities power engineering conference (AUPEC-2016), Brisbane, Australia, 25-28 Sept 2016

14. Adhikary P, Roy PK, Mazumdar A (2014) Multidimensional feasibility analysis of small hydropower project in India: a case study. Eng Appl Sci 9(1):80-84

15. LEAP:An Introduction to LEAP (2016)

16. Ates SA (2015) Energy efficiency and CO2 mitigation potential of the Turkish iron and steel industry using the leap (long-range energy alternatives planning) system. Energy 90:417-428

17. Klise GT, Stein JS (2009) Models used to assess the performance of photovoltaic systems. Sandia National Laboratories

18. Chapman RN (1996) Hybrid power technology for remote military facilities, Technical report, Sandia National Labs., Albuquerque, NM

19. iHOGA: General Information SOFTWARE iHOGA (2016)

20. Morgan T, Marshall R, Brinkworth B (1997) Aresa refined simulation program for the sizing and optimisation of autonomous hybrid energy systems. Sol Energy 59(4):205-215

21. Dufo-Lopez R, Bernal-Agustın JL, Contreras J (2007) Optimization of control strategies for stand-alone renewable energy systems with hydrogen storage. Renew Energy 32(7): $1102-1126$

22. iHOGA V2.2 User Manual (2016) http://personal.unizar.es/rdufo/images/ihoga/UserManual: pdf

23. Bernal-Agustın JL, Dufo-Lopez R (2009) Simulation and optimization of stand-alone hybrid renewable energy systems. Renew Sustain Energy Rev 13(8):2111-2118

24. Turcotte D, Ross M, Sheriff F (2001) Photovoltaic hybrid system sizing and simulation tools: status and needs. In: PV horizon, workshop on photovoltaic hybrid systems, Montreal, pp 2-5

25. SOMES 3.2: A Simulation and Optimization Model for renewable Energy Systems (2016). http://www.web.co.bw/sib/somes32description:pdf

26. Patel M, Pryor T (2001) Monitored performance data from a hybrid raps system and the determination of control set points for simulation studies. In: Proceedings of International Solar Energy Society: solar world congress, Adelaide, Australia, 25-30 Nov 2001

27. HOMER - Hybrid Renewable and Distributed Generation System Design Software (2015) http://www.homerenergy.com/

28. Mohammed OH, Amirat Y, Benbouzid MEH, Feld G, Tang T, Elbaset AA (2014) Optimal design of a stand-alone hybrid PV/fuel cell power system for the city of Brest in France. Energy Convers 1(2):1-7 
29. Normales et records des stations météo de France - Infoclimat. (2015)

30. ENERCON, energy for the world, Sept 2015. http://www.enercon.de/de-de/

31. Bashir M, Sadeh J (2012) Size optimization of new hybrid stand-alone renewable energy system considering a reliability index. In: Proceedings of the 11th international conference on environment and electrical engineering, May 2012

32. Johnson GL (2006) Wind energy systems. Gary L. Johnson

33. Amirat Y, Benbouzid MEH, Bensaker B, Wamkeue R (2007) Generators for wind energy conversion systems: state of the art and coming attractions. J Electr Syst 1(3):26-38

34. Kalogirou SA (2014) Photovoltaic systems. In: Kalogirou SA (ed) Solar energy engineering, 2nd edn. Academic Press, Cambridge, pp 481-540

35. Kusakana K, Vermaak HJ (2014) Hybrid diesel generator/renewable energy system performance modeling. Renew Energy 67:97-102

36. Skoplaki E, Palyvos J (2009) On the temperature dependence of photovoltaic module electrical performance: a review of efficiency/power correlations. Sol Energy 83(5):614-624

37. Benbouzid et al (2011) Concepts, modeling and control of tidal turbines. Marine renewable energy handbook. Wiley, ISTE, Paris

38. Benelghali S, Mekri F, Benbouzid MEH, Charpentier JF (2011) Performance comparison of three-and five-phase permanent magnet generators for marine current turbine applications under open-circuit faults. In: Proceedings of international conference on power engineering, energy and electrical drives, Malaga, Spain, 11-13 May 2011

39. Slootweg J, De Haan S, Polinder H, Kling W (2003) General model for representing variable speed wind turbines in power system dynamics simulations. IEEE Trans Power Syst 18(1): $144-151$

40. Mohammed OH, Amirat Y, Benbouzid MEH, Haddad S, Feld G (2016) Optimal sizing and energy management of hybrid wind/tidal/PV power generation system for remote areas: application to the Ouessant French Island. In: Proceedings of the 42th annual conference of the Industrial Electronics Society, IECON 2016, Florence, Italy, 24-27 Oct 2016

41. Haupt RL, Haupt SE (2004) Practical genetic algorithms. Wiley, New York

42. Kennedy J, Eberhart R (1995) Particle swarm optimization. In: Proceedings of the IEEE international conference on neural networks, Perth, Australia, no 4, pp 1942-1948

43. Poli R, Kennedy J, Blackwell T (2007) Particle swarm optimization. Swarm Intell 1(1):33-57

44. Yin PY, Wang JY (2006) A particle swarm optimization approach to the nonlinear resource allocation problem. Appl Math Comput 183(1):232-242

45. Lu Y, Liang M, Ye Z, Cao L (2015) Improved particle swarm optimization algorithm and its application in text feature selection. Appl Soft Comput 35:629-636

46. Rasoulzadeh-akhijahani A, Mohammadi-ivatloo B (2015) Short-term hydrothermal generation scheduling by a modified dynamic neighborhood learning based particle swarm optimization. Int J Electr Power Energy Syst 67:350-367

47. Parsopoulos KE, Vrahatis MN (2004) On the computation of all global minimizers through particle swarm optimization. IEEE Trans Evol Comput 8(3):211-224

48. Bansal J, Singh P, Saraswat M, Verma A, Jadon SS, Abraham A (2011) Inertia weight strategies in particle swarm optimization. In: Proceedings of the 3rd world congress on nature and biologically inspired computing, Salamanca, Spain, 19-21 Oct 2011

49. Sun J, Lai CH, Wu XJ (2011) Particle swarm optimisation: classical and quantum perspectives, 1st edn. CRC Press, Boca Raton 